\title{
Improved epoxy thermosets by the use of poly(ethyleneimine) derivatives
}

\author{
${ }^{1}$ Department of Analytical and Organic Chemistry, Universitat Rovira i Virgili, Tarragona, Spain, E-mail: angels.serra@urv.cat \\ ${ }^{2}$ Thermodynamics Laboratory, ETSEIB, Universitat Politècnica de Catalunya, Barcelona, Spain
}

\begin{abstract}
:
Epoxy resins are commonly used as thermosetting materials due to their excellent mechanical properties, high adhesion to many substrates and good heat and chemical resistances. This type of thermosets is intensively used in a wide range of fields, where they act as fiber-reinforced materials, general-purpose adhesives, highperformance coatings and encapsulating materials. These materials are formed by the chemical reaction of multifunctional epoxy monomers forming a polymer network produced through an irreversible way. In this article the improvement of the characteristics of epoxy thermosets using different hyperbranched poly(ethyleneimine) (PEI) derivatives will be explained.
\end{abstract}

Keywords: adhesives, epoxy, dendrimers

DOI: $10.1515 /$ psr-2016-0128

\section{General introduction}

Epoxy resins are commonly used as thermosetting materials due to their excellent mechanical properties, high adhesion to many substrates and good heat and chemical resistances. This type of thermosets is intensively used in a wide range of fields, where they act as fiber-reinforced materials, general-purpose adhesives, high-performance coatings and encapsulating materials. These materials are formed by the chemical reaction of multifunctional epoxy monomers forming a polymer network produced through an irreversible way [1]. In this article the improvement of the characteristics of epoxy thermosets using different hyperbranched poly(ethyleneimine) (PEI) derivatives will be explained.

\section{General concepts of epoxy thermosets}

The term epoxy or epoxide refers to compounds characterized by the presence of an oxirane or epoxy ring, a three-member ring containing an oxygen atom that is bonded with two carbon atoms as shown in Figure 1.

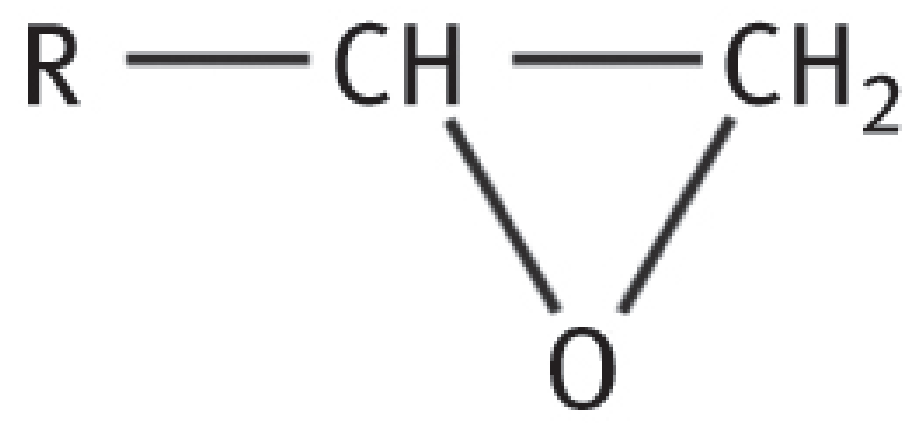

Figure 1: Chemical structure of epoxy ring

From the structural point of view of chemistry, epoxy resins are monomers or oligomers containing two or more epoxy groups in their structure. P. Castan [2] developed the first system based on the well-known diglycidyl ether of bisphenol A (DGEBA). The commercialization of this resin dates back to 1940 [3]. It is obtained by

Angels Serra is the corresponding author.

(C) 2017 Walter de Gruyter $\mathrm{GmbH}$, Berlin/Boston.

This content is free. 
the reaction of bisphenol A with epichlorohydrin in the presence of a strong base such as $\mathrm{NaOH}$. Depending on the ratio between reactants, the resulting molecular weight can be tuned in order to have different resins being possible to obtain liquid, waxy or solid DGEBA resins [4]. The reaction, still used nowadays, is depicted in Figure 2.

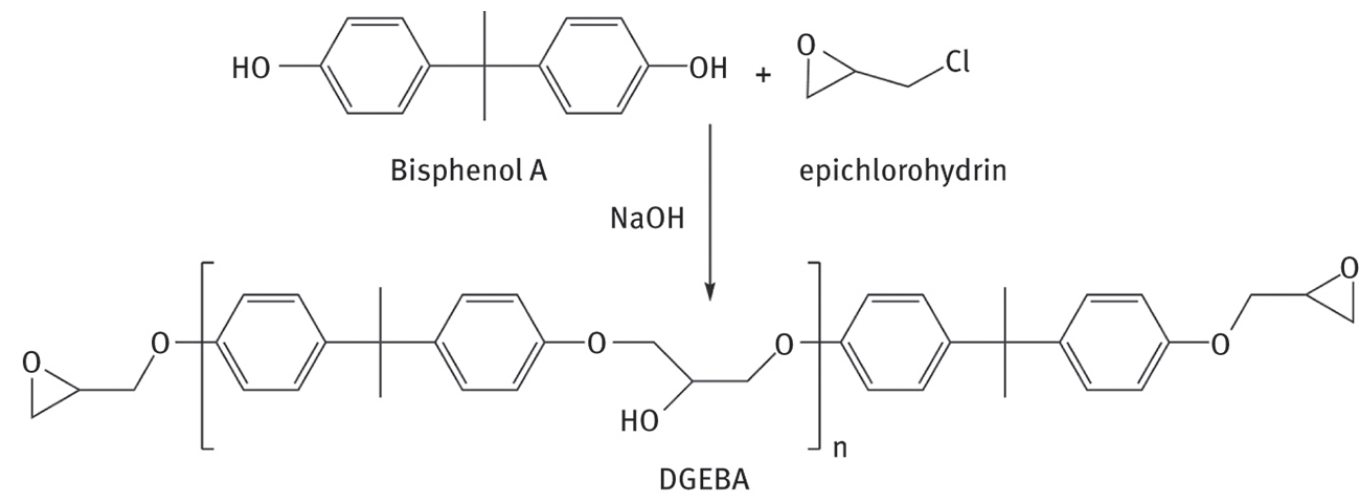

Figure 2: Synthetic scheme for the preparation of Bisphenol A epoxy resins

There are other types of resins with different structures that lead to materials with different characteristics. Some of the most typical resins are collected in Figure 3. The non-epoxy part of the molecule can have an aliphatic, cycloaliphatic or aromatic structure and the functionality, related to the number of epoxide groups, can also be varied.

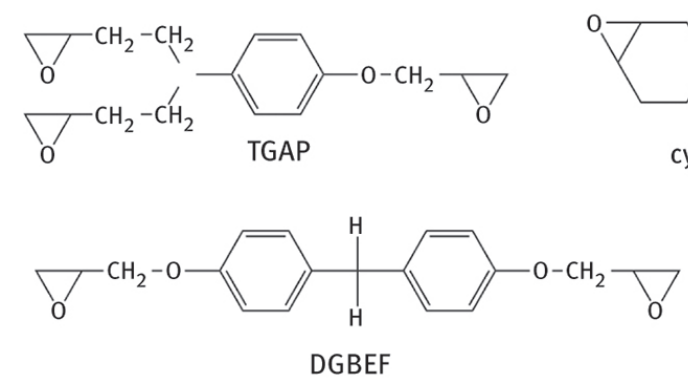

DGBEF

Figure 3: Structures of several commercially available epoxy resins

Epoxy resins are capable of reacting with different active compounds known as curing agents (with or without catalyst) or with themselves (via an initiator) to form solid, crosslinked materials. This transformation is generally referred to as curing.

From a fundamental point of view, thermosetting epoxy polymers may be defined as polymer networks obtained by a chemical reaction of monomers, which contain two or more epoxy groups per molecule (a functionality equal to or higher than 2) [5]. The functionality of an epoxy monomer is defined by the number of arms (bonding sites) that participates in the formation of the polymer network. The functionality of the epoxy monomers depends on the curing system used and will be discussed below, but a necessary condition for the formation of a network is that at least one of the monomers involved in the reaction has a functionality higher than two, since the global functionality of the system to reach a network structure is a minimum of 4 .

\section{Curing agents}

Crosslinked epoxy polymers are obtained by the reaction of epoxy monomers with curing agents (co-monomers or initiators). Epoxy polymers can be produced by step or chain growth polymerizations or, eventually, by a combination of both mechanisms [5].

Step growth polymerization (polycondensation) proceeds via a step-by-step succession of elementary reactions between reactive sites. Each independent step causes the disappearance of two co-reacting sites and creates a new covalent bond between a pair of functional groups. In this case curing agents like amines, alcohols, anhydrides, isocyanates or acids have been used in stoichiometric ratio [6]. 
Chain growth polymerization (ring opening) is characterized by the occurrence of initiation, propagation, chain transfer and termination steps. In the case of epoxides, the initiation step produces an ion (either an anion or a cation) that is called the active center of the polymerization. The ion may be generated by thermal treatment or by an adequate source of irradiation. Once active centers are generated, they produce primary chains by the consecutive addition of monomers through the propagation step of the reaction.

Polycondensation curing mechanisms require an accurate knowledge of the stoichiometry of the system. Among them, the most used curing agents for epoxy resins are primary and secondary amines. In this system, DGEBA is bifunctional and a requirement for the amines is that they must be multifunctional (more than two reacting groups). Considering that primary amines account for a functionality of two and secondary for a functionality of one, usually primary diamines are used. The reaction of epoxy with amines is depicted in Figure $4[6]$.

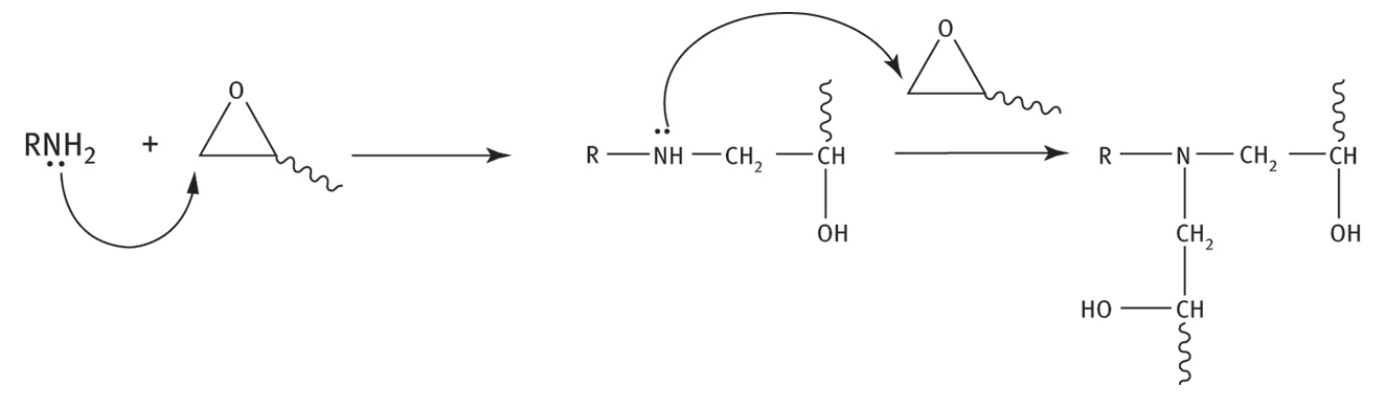

Figure 4: Reaction of a primary amine with epoxides

Primary and secondary aliphatic amines react rapidly with epoxy groups at low temperature to form threedimensional crosslinked structures. However, they can also be cured at higher temperatures to provide a more densely crosslinked structure with better mechanical properties, elevated-temperature performance and chemical resistance. Other amines, such as aromatic or cycloaliphatic, are less reactive and generally require higher curing temperatures.

After amines, acid anhydrides are the second most used group of curing agents. Among the most common anhydrides, phthalic anhydride (PA, a), tetrahydrophthalic anhydride (THPA, b), methyl tetrahydrophthalic anhydride (MTHPA, c) and nadic methyl anhydride (NMA, d) can be mentioned (Figure 5).<smiles>O=C1OC(=O)c2ccccc21</smiles>

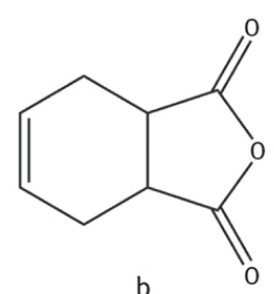<smiles>CC1CC2C(=O)OC(=O)C2C1</smiles><smiles>CC=C1C2C=CC1C1C(=O)OC(=O)C21</smiles>

Figure 5: Chemical structure of anhydrides used as curing agents of epoxy resins

The reaction of anhydrides with epoxy groups has been extensively studied and follows a complex mechanism, with several competitive reactions capable of taking place [7, 8]. The limitation of the use of anhydrides as curing agents is the low reactivity and, therefore, curing has to be carried out at high temperatures to obtain optimal properties [9]. The presence of catalysts such as tertiary amines, metallic salts and imidazoles can accelerate the curing and overcome this drawback [10].

The main reaction that takes place on curing epoxide/anhydride mixtures without amine is illustrated in Figure 6. The first reaction is the opening of the anhydride ring by reaction of a hydroxyl group to form the monoester (1) and subsequently the nascent carboxylic group reacts with the epoxy to provide an ester linkage (2). The reaction proceeds by the presence of existing hydroxyl groups (3). 
1)<smiles>[R]C(=O)O[C@H](C)OCCN(CC)C(=O)OC(C)C</smiles>

2)<smiles>[R]C(=O)OC(C)CCCCCC1CO1</smiles>

3)<smiles>[R]C(=O)OCC(C)O</smiles><smiles>[R]C(=O)OC(=O)C(=O)OCC(C)OC(=O)C(=O)OC(C)C</smiles>

Figure 6: Uncatalyzed curing mechanism of epoxides with anhydrides

In the presence of tertiary amine a different mechanism occurs (Figure 7). It is proposed that the tertiary amine reacts with the epoxy monomer and forms a zwitterion that contains a quaternary nitrogen atom and an alkoxide (1). The alkoxide rapidly reacts further with an anhydride group, leading to a carboxylate anion (2). Propagation occurs through the reaction of the generated carboxylate with an epoxy group and the formation of a new alkoxide anion (3). There is still no definite validation regarding the termination step and whether the initiator remains chemically attached during the whole course of the reaction. Some authors describe an irreversible bonding of the initiator [11], but there is disagreement on this point [12, 13].

1)

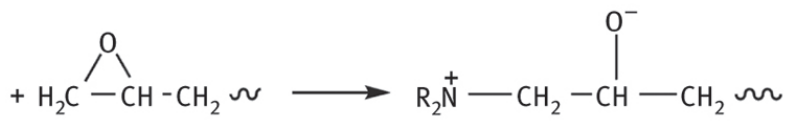<smiles>[R16]CC([O-])CCCCCC(=O)OC(C)C[18O]</smiles>

3)<smiles>[R]C(=O)OC(CS)C[N+]#N</smiles><smiles>CCCC1CO1</smiles><smiles>[Y16]C[C@H](CC)OC([R])=O</smiles>

Figure 7: Curing mechanism of epoxides with anhydrides in the presence of tertiary amines 
The other main group of curing agents used is the one of initiators. Commonly used initiators include Lewis bases such as tertiary amines or imidazoles for anionic chain polymerization, and Lewis acids such as boron trifluoride complexes or other metal salts. These initiators are used in catalytic amounts and promote the homopolymerization of epoxides via the ring-opening polymerization (ROP) [14]. This ring-opening mechanism is similar in terms of the kinetics to poly-addition since it presents an initiation step, a propagation and finally a termination, but mechanistically it is more complex and leads to the introduction of heteroatoms in the network structure.

In these initiated curing systems, the functionality of the epoxide group is two and therefore the global functionality of a diepoxy resin is four. Thus, from a diepoxide, crosslinked structures can be obtained by the use of the adequate initiator and conditions.

Anionic polymerization can be promoted by several initiators with high nucleophilic character or strong basic characteristics, but in the field of epoxy thermosets the most extended anionic initiators are tertiary amines [1], such as 1-methyl imidazole (1-MI) [15] or 4-(N,N-dimethylamino)pyridine (DMAP) [16] (Figure 8).

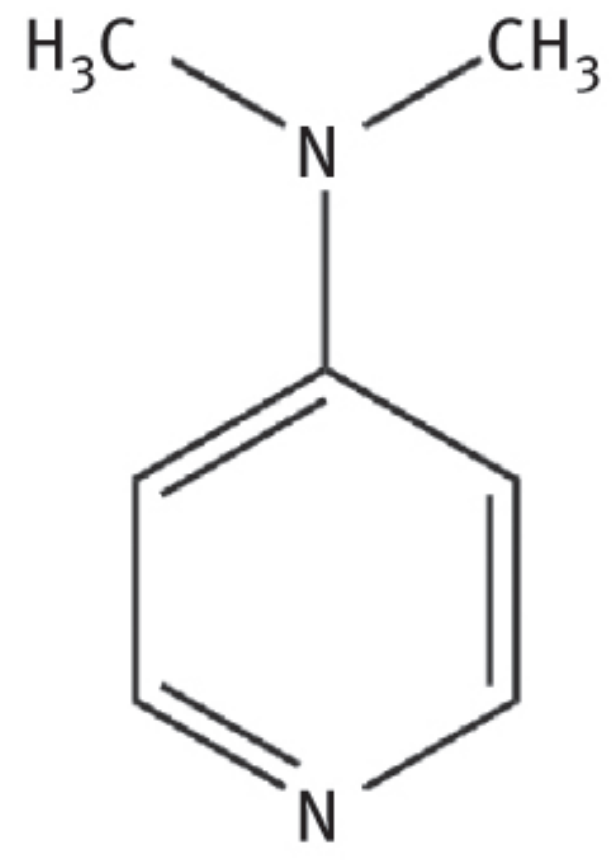

DMAP

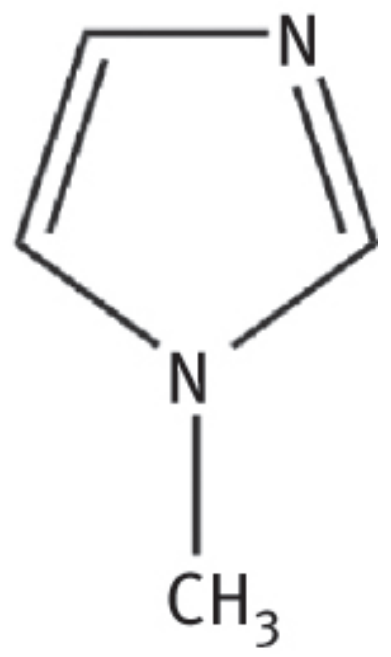

1-MI

Figure 8: Chemical structures of tertiary amines used as anionic initiators

The curing mechanism initiated by tertiary amines is depicted in Figure 9. As can be seen, the opening of the epoxide by the nucleophilic attack of the amine forming an alkoxide is the first step. Initiation and propagation proceed by nucleophilic substitution $\left(\mathrm{S}_{\mathrm{N}} 2\right)$ and as a consequence nucleophilic attack occurs in the lesssubstituted carbon.

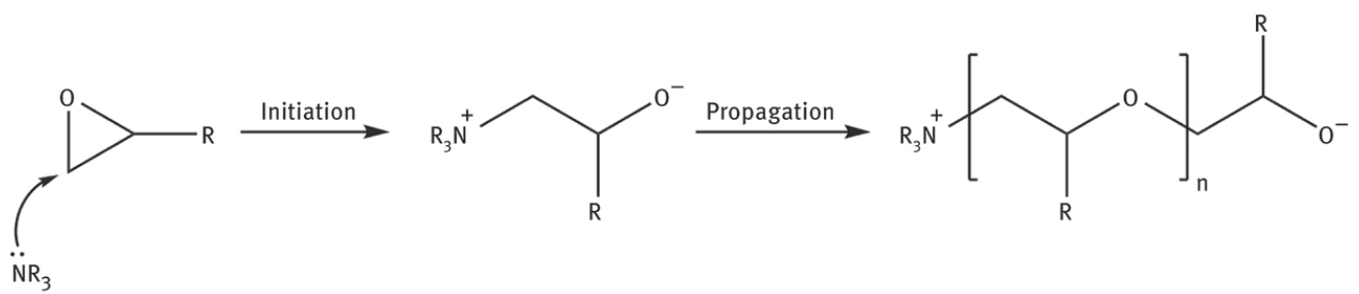

Figure 9: Anionic ring-opening homopolymerization of epoxides initiated by a tertiary amine

Ooi etal. [17] observed by differential scanning calorimetric (DSC) studies two exothermic peaks during the curing process of $\mathrm{N}$-alkyl substituted imidazole-DGEBA formulations. These results indicated that the curing mechanism represented in Figure 9was more complex. The cause of the additional peak was associated with imidazole regeneration by $\beta$-elimination or $N$-dealkylation process, which then reinitiates the polymerization, as discussed in Figure 10. 


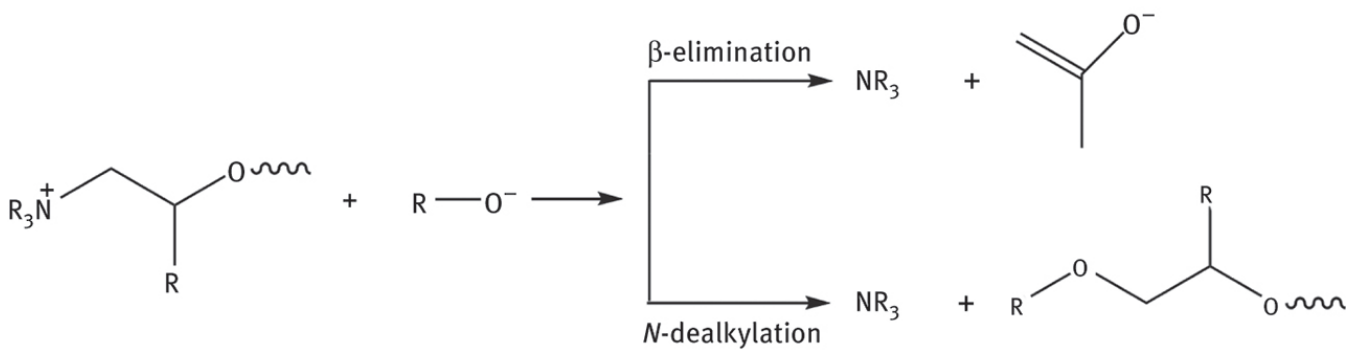

Figure 10: Possible pathways of tertiary amines regeneration

Moreover, in previous studies it could be demonstrated that the presence of species that can coordinate with epoxides (such as hydroxyl groups) promotes the initiation step, speeding up the reaction due to the interaction between the hydroxyl group and the oxygen in the oxirane ring, which helps increase the positive charge in the oxirane ring methylene carbons (Figure 11). The imidazole regeneration can be also favored by the presence of hydroxyl groups $[18,19]$.

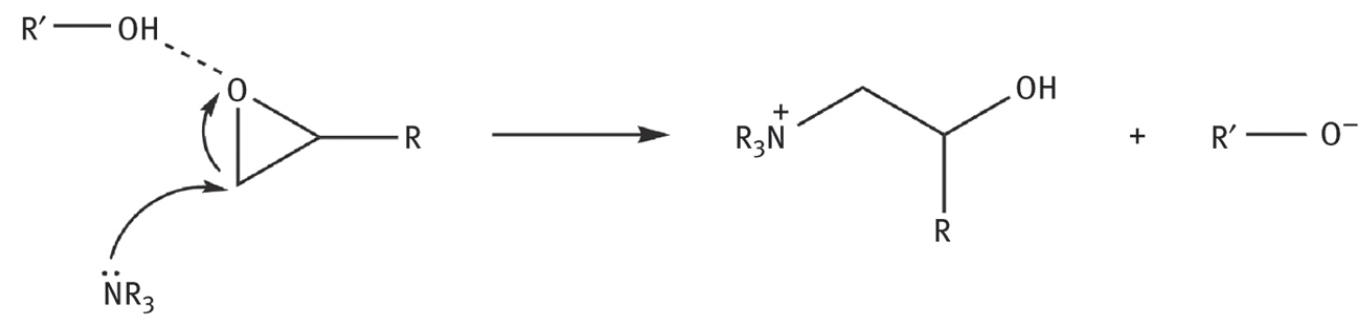

Figure 11: Nucleophilic opening of the epoxide group favoured by coordination with hydroxyl groups

If the initiation step is catalyzed by Brönsted or Lewis acids, the propagation takes place via a cationic mechanism. $\mathrm{TiCl}_{4}, \mathrm{AlCl}_{3}, \mathrm{ZnCl}_{2}, \mathrm{BCl}_{3}, \mathrm{SiCl}_{4}, \mathrm{FeCl}_{3}, \mathrm{MgCl}_{2}$ and $\mathrm{SbCl}_{5}$ are Lewis acids used as catalysts, but the most extended one is the $\mathrm{BF}_{3} /$ amine complex [20]. In recent years also lanthanide and rare earth metal triflates have demonstrated to be good cationic initiators [21-24].

Figure 12shows the mechanism of propagation for the cationic polymerization of epoxides. In this case, there are two propagation mechanisms that coexist: active chain end (ACE) and activated monomer (AM) [25]. Both mechanisms start by the coordination of the initiator with the epoxide to promote the ring opening. The ACE mechanism consists in the reaction between an activated epoxide and a nonactivated one. In that way, the activated epoxide is always linked to the growing chain forming a cyclic oxonium cation. On the contrary, the AM mechanism requires a hydroxyl group to first open an activated epoxide. Then, there is an intermolecular interchange of protons with an epoxide that now becomes activated. Thus, the monomer is always the activated epoxide.

Actice chain end $(A C E)$

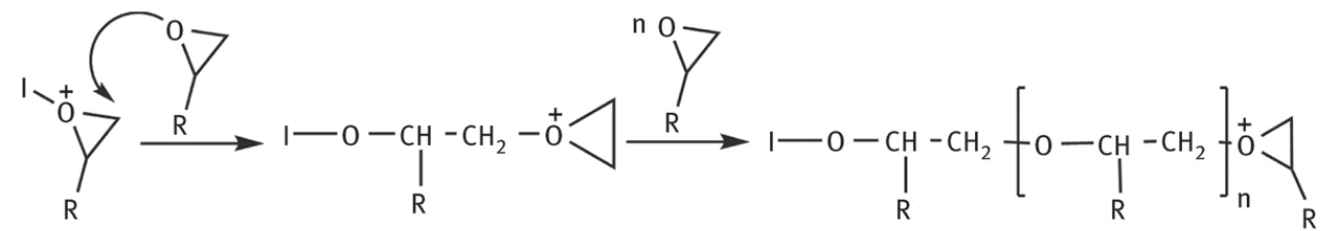

Activated monomer (AM)<smiles>[R]OCC([R])OI(C)[C@H]1CO1</smiles>

Figure 12: Active chain end (ACE) and activated monomer (AM) propagation mechanisms for the cationic polymerization of epoxides

All these systems described constitute a two-component system in which the monomer and curing agents are stored separately and they are mixed in the correct quantity just prior to use. However, one-component systems in which the mixture of epoxy resin and curing agent is commercially supplied, also called one-pot resins, 
have considerable advantages over the others, since they are easier to use. One-pot epoxy resins require a latent curing agent, which does not react at room temperature, but reacts with epoxy resins under external stimulation, heat or irradiation [26]. Thermal latent curing agents can act mainly by two different mechanisms: the first one is based on their low compatibility in the epoxy resin because of their crystalline character or by encapsulation of the active species [27]. The second mechanism is based on the use of a precursor compound, inactive at room temperature, but which under triggering by heat transforms into an active curing agent [28]. Photoirradiation can also lead to the formation of active species, which originate homopolymerization by cationic or anionic processes [29]. Although photoirradiation is a more convenient way of triggering, from the point of view of energy savings, it presents some disadvantages, such as the curing of thick samples or with a complex geometry [30]. The initiation by heat is easier from the experimental point of view and can be applied to thicker samples or to hidden parts of surfaces.

The selection of the curing agent is the key point in the application, workability of the curing mixture, characteristics of the final thermosets and other factors.

\section{Characteristics of epoxy thermosets}

The degree of crosslinking and the nature of the bonds in the cured epoxies give them many desirable characteristics that have placed these thermosets as the standard option for a variety of applications such as adhesives, coatings, composites for structural applications, and so on.

Some of the most important characteristics of these materials are the absence of volatile matter on curing and the capacity to adhere to most substrates due to the presence of polar groups like hydroxyl or ether [10]. In addition, epoxy resins are resistant to thermal degradation and are stable to the attack by corrosive chemicals. These properties are related to the covalent bonds present in the network, which define their stability. The presence of groups that can be removed by chemical reactions using weak alkalis, strong acids and organic solvents reduce the chemical resistance [31,32]. Moreover, the addition of cleavable linkages in the network structure allows thermosetting materials to be removed under thermal controlled conditions [33-35].

Epoxy thermosets are amorphous and highly crosslinked materials. The crosslinking density is a key parameter in determining the mechanical properties of an epoxy resin after cure. The higher crosslinked density allows these thermosetting materials to have high glass transition temperatures and useful properties like high values of hardness, tensile strength, shear strength or Young's modulus.

However, in terms of structural applications, they have some disadvantages that limit their range of applications. Epoxy resins are in general brittle due to their high crosslinked character, which confers low impact strength and poor resistance to crack propagation [2]. The fracture resistance decreased with increasing crosslinking density [35]. Moreover, the tight structure implies a shrinkage that is undergone during the curing process, which finally leads to the apparition of stresses and defects in the material. The crosslinked nature enhances the thermal resistance, so they cannot be removed from a substrate without damaging it. In coatings technology, the resistance to scratch is another interesting issue to be improved. Thus, new strategies to overcome these drawbacks are needed, but these strategies should not compromise other properties.

\subsection{Toughness}

Toughness of a specimen refers to the total energy required to cause failure, i.e. the total area under the stress-strain curve or the energy absorbed in an impact test. Toughening of the epoxy resins by the addition of toughening agents or modifiers helps improve the amount energy absorption capacity. As a result, tremendous effort has been focused on improving the toughness of such materials during the past decades and many reviews in this area are available [36-38].

There are many approaches for improving toughness in epoxy resins, which include: a) chemical modification of the network structure to make it more flexible, b) increasing the molecular weight of the epoxy resin to improve the molecular weight between crosslinks, c) lowering the crosslink density of the matrix by adjusting the ratio of epoxy resin/crosslinking agent, d) adding reactive diluents, e) adding toughness modifiers in the formulation or f) incorporating inorganic fillers/reinforcements into the neat resin [36].

The most promising strategy for increasing the toughness of epoxy thermosets is the incorporation of plasticizers, like thermoplastic or rubbers, which increase the flexibility of the final network by the incorporation of a second dispersed phase $[39,40]$. However, the addition of these modifiers usually compromises the modulus and thermomechanical characteristics of the thermosets, leading to a reduction of Young modulus and $T_{g}$, and worsening the processability of the formulation by increasing its viscosity [36]. 
Another method of preventing the crack from freely developing after impact is the addition of a modifier that induces the formation of particles that absorb the impact energy and deflect the crack. The formation of micro/nanostructures in multicomponent thermosets can further optimize the interactions between the thermosetting matrix and the modifiers and thus the mechanical properties of materials can be significantly improved. This is known as "toughening by micro/nanostructures" and can be achieved, among other procedures, following the chemical-induced phase separation methodology (CIPS) [41, 42]. It starts from an initial homogeneous mixture composed of the resin, curing agent and modifiers. On curing, a blend of epoxy matrix filled with rubber or thermoplastic microspheres is formed, with a final size of these particles controlled by the viscosity of the reacting mixture during curing [43].

Alternatively, new strategies as the incorporation of hyperbranched polymers (HBPs) [44, 45] or multiarm star polymers (SPs) [42] have been applied with good results in improving toughness without affecting the other properties of the resin [46]. The improvement in toughness in the case of HBPs is attributed either to the flexibilizing effect induced by the homogeneous incorporation of the HBP [47] or to the local inhomogeneities created in the crosslinked network by the formation of phase-separated nanoparticles with good interfacial adhesion between phases [48]. The particles hinder the propagation of a certain crack in the material as seen in Figure 13. Since the interaction between phases plays a key role in this toughness reinforcement mechanism, the structure of the HBP must be carefully selected in order to obtain the desired properties.

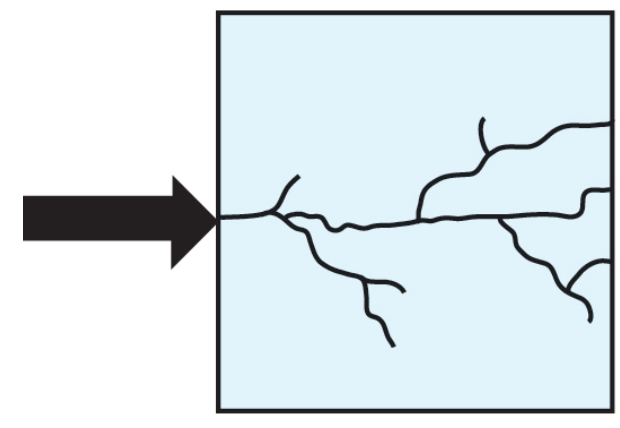

a

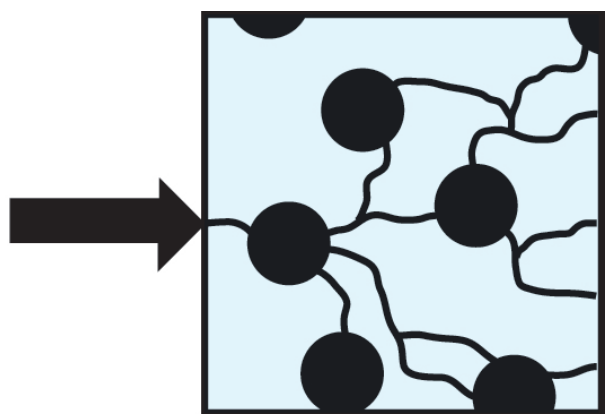

b

Figure 13: Crack propagation in materials: a) without particles and b) with dispersed particles

\subsection{Shrinkage}

When any type of monomers undergoes polymerization and crosslinking, shrinkage occurs throughout the cure process. Shrinkage is the reduction in volume brought about by increase in density. The curing process of epoxy resins entails shrinkage, which is a critical point in the field of coatings since it can lead to the appearance of internal stresses and consequently to defects in the materials, such as microvoids, microcracks or warping [49]. For this reason, the reduction of stresses is an important goal since the protection capability is reduced when thermosets are used as coatings.

One should distinguish between thermal and chemical shrinkage. Thermal shrinkage occurs in thermal curing because after curing the thermosets obtained at high temperature should be cooled down until room temperature and therefore the contraction is difficult to avoid. On the other hand, chemical shrinkage occurs because of the formation of new covalent bonding in the reactions taking place during the curing process. In general, as the monomer polymerizes, its density changes as a direct result of the bond changes being affected during polymer formation. Usually, the new bonds formed are shorter in the polymer than the distances between monomers [50]. This shrinkage is caused by the chemical reactions taking place during curing and it is described that the shrinkage during ROP is lower than chain growth and step growth polymerizations [50]. This is due to the fact that per each Van der Waals distance that becomes a covalent bond, there is one covalent bond going to a nearly Van der Waals distance (Figure 14). Thus, the use of ROP is a good strategy to produce the minimally shrinking epoxy thermosets.

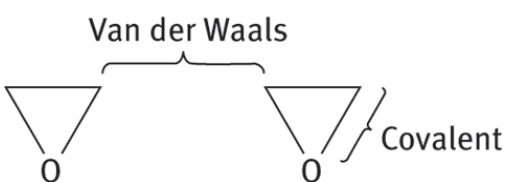

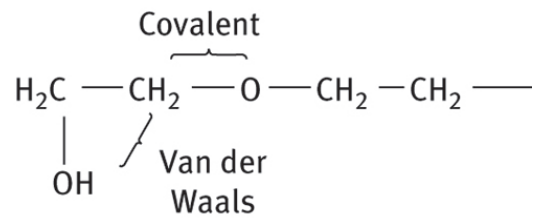


Figure 14: Changes of distances before and after ring opening polymerization

Many approaches have been developed to solve the shrinkage issue related to the chemical reactions occurring during the curing process like the addition of inorganic inert charges (silica, quartz or mica) or polymeric charges (polyurethane foams, PVC or polystyrene). Unfortunately, the main problem of this strategy is that the $T_{g}$ of the resulting thermosets decreases dramatically, reduces toughness, increases the viscosity and worsens the material properties, thereby limiting their range of applications [2].

New strategies such as the addition of HBPs as modifiers in epoxy thermosets can reduce the shrinkage during curing by reducing the internal stresses [51]. The incorporation of HBPs in the network decreases the coefficients of thermal expansion (CTEs) due to the higher degree of crosslinking coming from the high number of reactive groups in the HBP and does not reduce the $T_{g}$ of the final materials [52]. Moreover, it has been reported that the increase in the amount of HBP added to the formulation reduces not only the global shrinkage but also the shrinkage after gelation, which is the true responsible of the apparition of stresses. [51]. It is worth noting that after the gelation, the material loses its mobility and therefore the shrinkage produced after gelation produces tensile, compressive and shear forces within the resin.

\subsection{Reworkability}

The concept of reworkability in thermosets is related to the ability of the material to break down under controlled conditions in order to be removed from a given substrate (Figure 15), but it does not mean that the polymeric material can be reused or recycled [34].
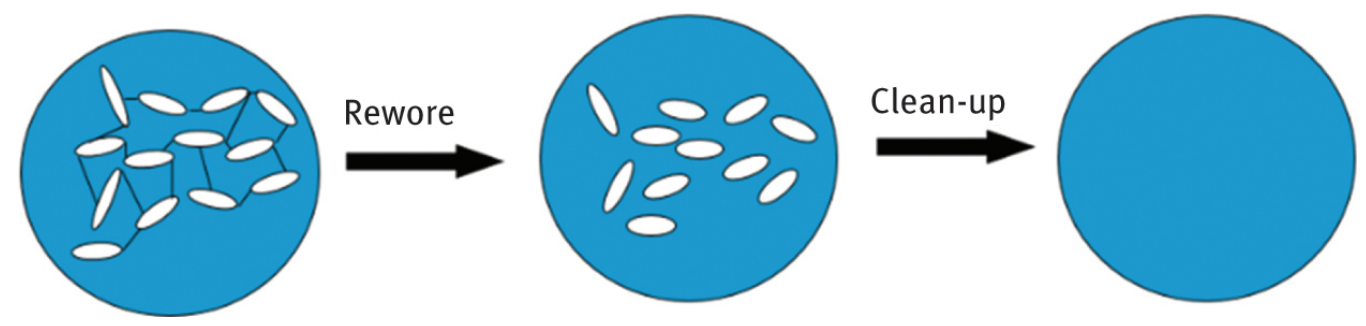

Figure 15: Scheme of the process of the elimination of a reworkable coating

The decomposition of the degradable linkages upon heating is expected to lead to a decrease in crosslinking density and modulus of the adhesive or coating, allowing its removal and replacement. The optimal temperature range for safe rework operation is desired to be within $200-250{ }^{\circ} \mathrm{C}[33,53]$.

In order to obtain thermally reworkable epoxy thermosets, one of the first approaches was the introduction of disulfur linkages in the amine curing agent, which allows the fragmentation of the thermoset with temperature [54]. Other authors proposed the introduction of thermally labile groups in the structure of the resin [55, 56]. The introduction of ester groups improves the reworkability since they can be broken by a $\beta$-elimination process (Figure 16) at a temperature of about $235^{\circ} \mathrm{C}$ [33].<smiles>[R]C(=O)OCCOC(C)(C)C</smiles><smiles>CC(=O)O</smiles><smiles>C=C(C)C</smiles>

Figure 16: Mechanism of pyrolytic $\beta$-elimination of esters

Alternatively, there also exists the possibility of introducing groups that can be eliminated by chemical reactions. This is the so-called "chemical reworkability". There are many strategies based on this principle. For instance, the introduction of olefinic unsaturation in the structure of the resins allows the cleavage of the 
network by oxidation of the double bonds with permanganate. If the groups introduced are carbamates, the cleavage is carried out by strong acid treatment [57].

Other examples are the use of epoxy resins with ketal groups in their structure, which can be hydrolyzed after acid treatment [58] or the copolymerization of epoxy resins with spirocyclic $\gamma$-bislactone obtaining thermosets that can be completely solubilized in $1 \mathrm{M}$ ethanolic $\mathrm{KOH}$ solutions [59].

\subsection{Scratch resistance}

In many coating systems, the uppermost layer is a thin coating, which not only protects the underlying layers or substrate from chemical and UV degradation, but also provides protection from mechanical damage that can result in surface blemishes/scratches [60]. Excellent scratch-resistance coatings are characterized by large plastic deformation, small cracks and high elastic recovery [61].

There are two main ways of improving the scratch resistance of organic coatings: one is to optimize the polymer lacquer components and the other is to reinforce the coating by embedding fillers into them [62]. The addition of nanosized silica and alumina particles having diameters of 10-50 $\mathrm{nm}$ represents an attractive alternative to conventional fillers. Because of their nanometer size and their large active surface, it can be expected that polymeric nanocomposites exhibit markedly improved properties as compared to pure polymers or conventional composites. Thus, different inorganic and organic nanopowders, such as $\mathrm{SiO}_{2}, \mathrm{Al}_{2} \mathrm{O}_{3}$ or $\mathrm{ZrO}_{2}$, have been employed, yielding considerable mechanical reinforcement [63].

Hybrid organic-inorganic nanocomposites have drawn considerable attention, in recent years, because they combine the advantages of an organic polymer (flexibility, light weight, good impact resistance and good processability) and inorganic materials (high mechanical strength, good chemical resistance, thermal stability and optical properties) [64]. The formation of inorganic domains generated in situ for enhanced surface scratch resistance seems to be a very promising approach toward new, multifunctional technical coatings [65]. The generation of nanostructures in the polymer matrix by sol-gel processes leads to a fine dispersion of the inorganic phase into the epoxy matrix, which could be advantageous in comparison to the addition of performed inorganic nanoparticles, improving scratch characteristics.

Nowadays, the combined use of HBPs and sol-gel reactions in the preparation of nanocomposites seems to be advantageous as they can allow better interaction of the organic phase with the inorganic particles [66, 67]. The multifunctional HBP structure allows to prepare silica hybrid coatings with a strong increase in surface hardness and scratch resistance.

\section{Dendritic polymers}

In the 1980s, a kind of highly branched three-dimensional macromolecules, also named dendritic polymers, was born and gradually became one of the most interesting areas of polymer science and engineering [68]. Dendritic architecture is recognized as the main fourth class of polymer architecture after traditional types of linear, crosslinked and chain-branched polymers that have been widely studied and industrially used [69].

Dendritic molecules are composed of repeating units emanating from a central core. When the structure of the molecule is perfectly symmetric around the core and adopts a spherical three-dimensional morphology, a dendrimer is formed. In contrast, the presence of some imperfections results in a hyperbranched polymer (HBP). A schematic representation of dendrimers and HBPs is represented in Figure 17.

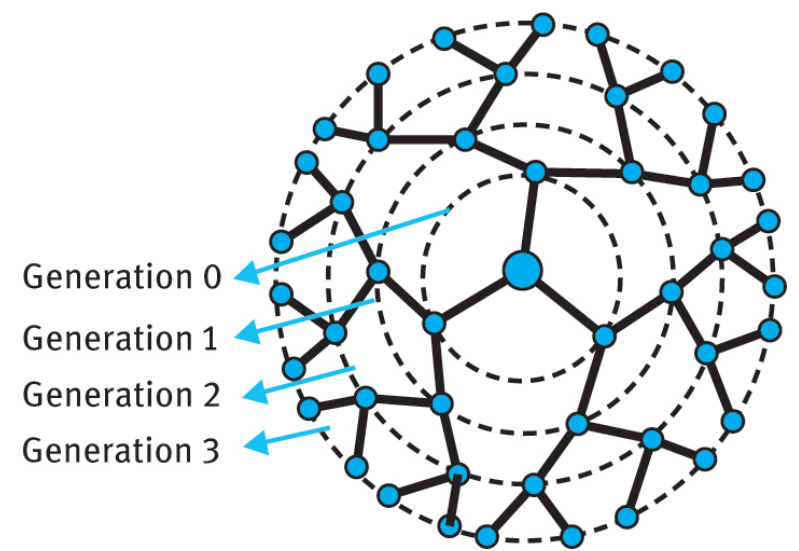

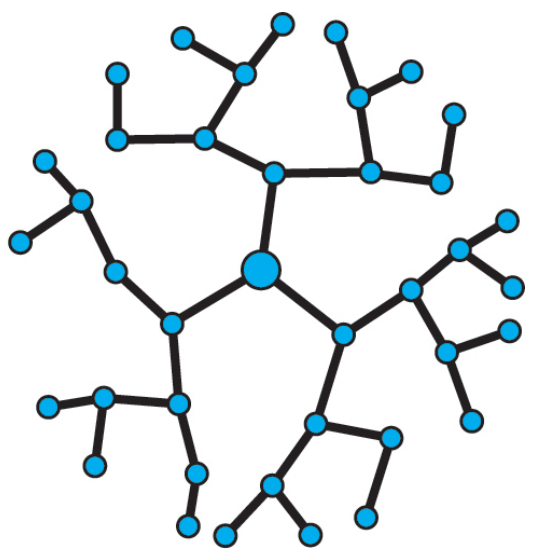

Authenticated | angels.serra@urv.cat author's copy Download Date | 8/7/17 1:18 PM 
Figure 17: Schematic representation of a dendrimer and a hyperbranched polymer

In a perfectly branched dendrimer, only one type of repeating unit can be distinguished, apart from the terminal units. However, HBPs present three different types of repeating units, named D, L and T, as illustrated in Figure 18.

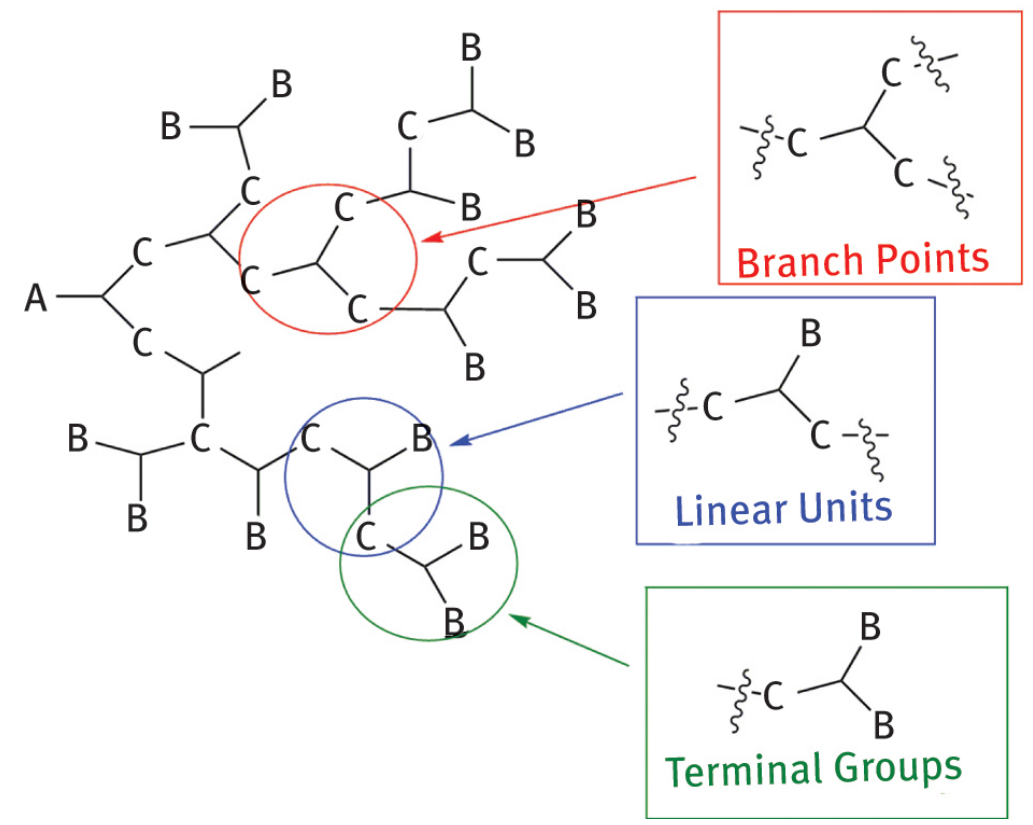

\section{Units}

D

Figure 18: Different units present in a $\mathrm{HBP}$ obtained from the polymerization of an $\mathrm{AB}_{2}$ monomer

The degree of branching (DB) is a structural parameter used to characterize the topology of dendritic polymers and is one of the most important because it has a close relationship with polymer properties such as free volume, chain entanglement, mean-square radius of gyration, glass transition temperature $\left(T_{g}\right)$, degree of crystallization (DC), capability of encapsulation, mechanical strength, melting/solution viscosity, biocompatibility and self-assembly behaviors [70,71]. Fréchet and coworkers [72] defined the DB as the ratio of the molar fraction of branched and terminal units relative to that of the total possible branching sites.

$$
D B=\frac{D+T}{D+T+L}
$$

where $\mathrm{D}$ is the number of fully branched units and $\mathrm{L}$ is the number of partially reacted units. The value of the DB varies from 0 for linear polymers to 1 for dendrimers or fully branched HBPs (see Figure 4).

Dendritic polymers are characterized by special features that make them promising candidates for a number of applications. One of the most interesting physical properties is their lower viscosity in comparison with their linear analogues, which is a consequence of the architecture of the molecules [73]. The relationship between molecular weight and viscosity for various polymer topologies is represented in Figure 20. Dendrimers in solution reach a maximum of intrinsic viscosity as a function of molecular weight as their shape changes from an extended to a more compact globular structure, especially at high molecular weights [74, 75].<smiles>[3H][Te][Te][Te][Te][Tl][I][3H]</smiles>

Linear Polymers<smiles>[3H]OP([3H])OP([3H])OP([3H])OP([3H])[3H]</smiles>

Hyperbranched Polymers

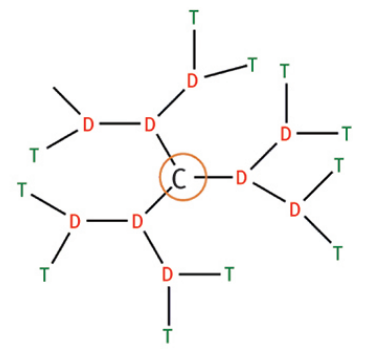

Dendrimers
0
0.5-0.55

1 
Figure 19: Values of the DB of linear polymers, HBPs and dendrimers

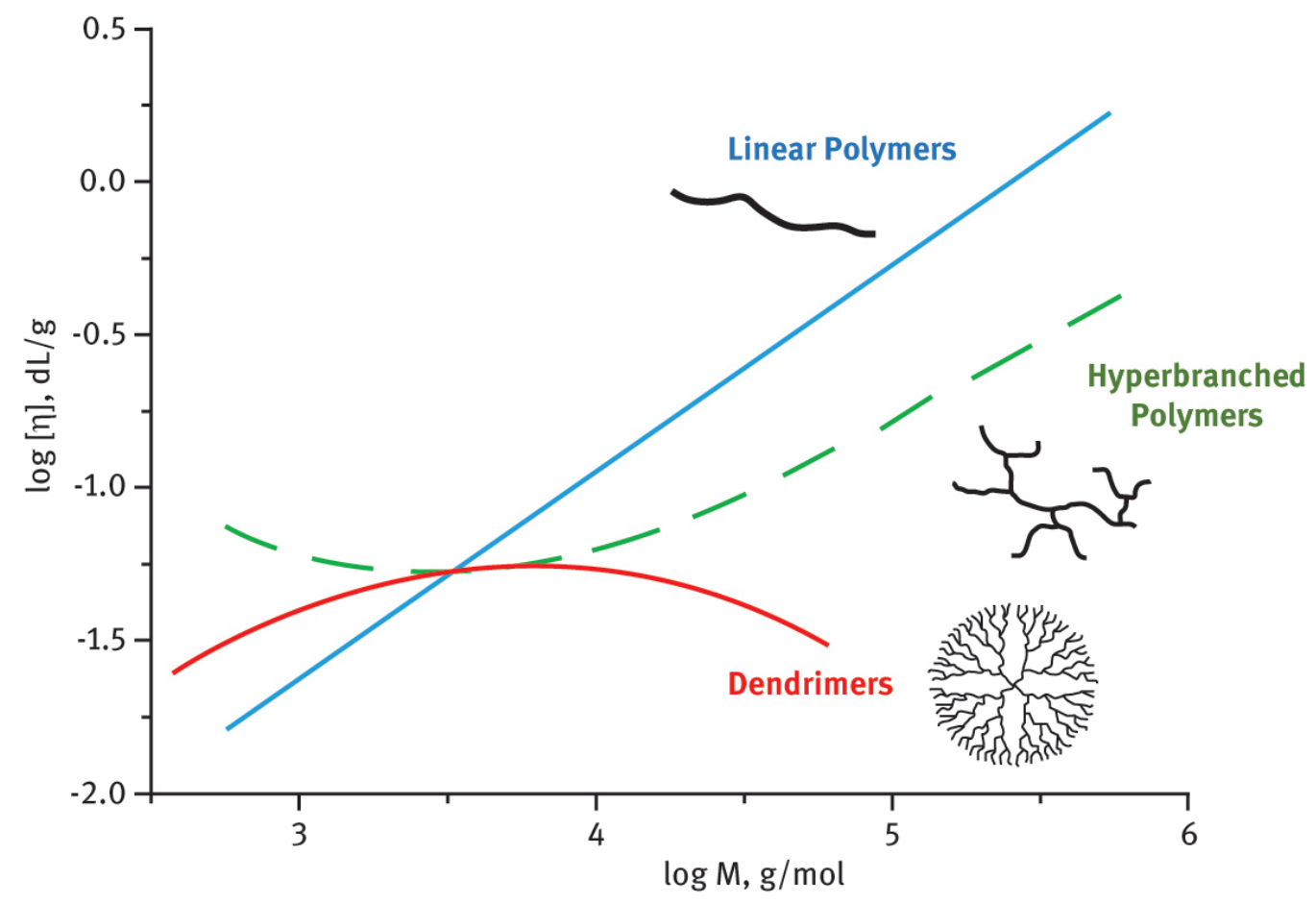

Figure 20: Relationship between intrinsic viscosity $(\eta)$ and molecular weight $(\mathrm{M})$

Well-defined structures require a stepwise synthesis and dendrimers are usually prepared by an iterative synthesis, with the purification of intermediate stages or generations while hyperbranched molecules can be synthesized in one step. This characteristic and their good properties such as low viscosity, good solubility and good chemical reactivity make HBPs suitable products for a larger application scale in typical technological fields like coatings and adhesives [76].

\subsection{Hyperbranched polymers}

HBPs are highly branched three-dimensional macromolecules with a large number of end groups (Figure 19) [77]. They have special properties, which are key to their industrial applications. As mentioned before, one of them is low viscosity compared with their linear analogues.

Besides, HBPs have high chemical reactivity and enhanced solubility when compared to their linear analogues. They also exhibit enhanced compatibility with other polymers as has been demonstrated by blending studies [73]. Hyperbranched materials also have outstanding mechanical properties such as modulus, tensile strength and compressive moduli, which reflect the compact highly branched structures [73]. Owing to those special properties, HBPs have been used as rheology modifiers or blend components [44, 78], tougheners for thermosets [43, 45] and crosslinking or adhesive agents [79]. Also, HBPs have been used as the base for various coating resins [80], including powder coatings [81], flame-retardant coatings [82] and barrier coatings for flexible packaging [83].

\subsection{Star polymers}

Dendritic polymers with a single branch point and all arms exhibiting low degrees of compositional heterogeneity with respect to composition, molecular weight and molecular weight distribution are named star polymers (SPs) [84]. Basically, SPs consist of linear polymeric chains radiating from one single branched point, called "core" or central nodule, and which can itself be polymeric. If the arms are identical, the SP is said to be regular. If the adjacent arms are composed of different repeating subunits, the SP is said to be miktoarm. The copolymeric nature of the arms leads to the so-called copolymeric stars (Figure 21). For the preparation of multiarm SPs, a multifunctional core is needed. The lower cost of HBPs, the presence of reactive final groups and their easy synthesis from commercially available monomers make them adequate cores for their preparation. 


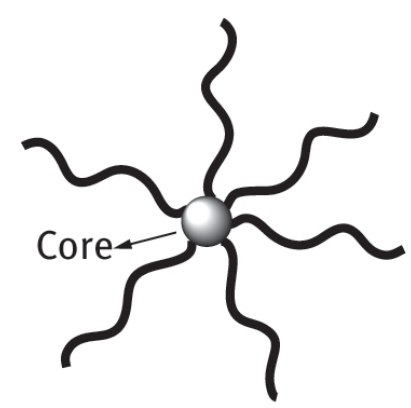

Regular star

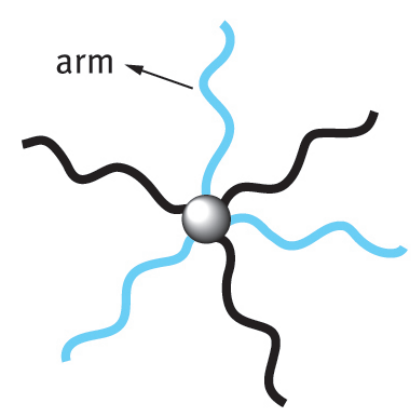

Miktoarm star

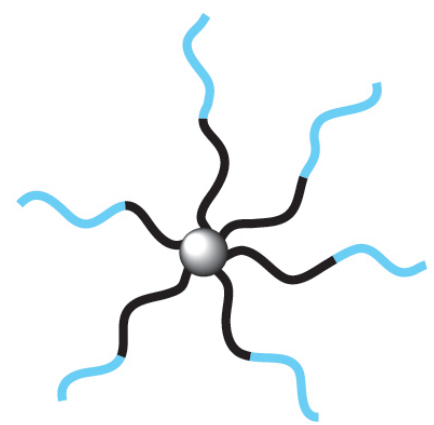

Copolymeric star

Figure 21: Schematic representation of star polymer structures

SPs resemble more closely the hard sphere model, especially when the numbers of arms in the SP are high. The hard sphere character of SP is directly correlated to entanglement. If the number of arms is high, the entanglement decreases and it is lower than in linear polymers, causing lower intrinsic viscosity of these materials as compared to linear polymers of the same molecular weight, which is one of the main features of SPs [75, 85 , 86].

Owing to their compact structures and high segment density, SPs have gained increasing interest. Nowadays, the incorporation of biocompatible segments on the star copolymer structures is of particular interest for biomedical applications [87]. Moreover, SPs have potential applications as components of different types of complexes, hydrogels, networks, ultrathin coatings, thermoset modifiers, etc. [88]-[90].

\section{Modified epoxy thermosets by using HBPs and other highly branched topologies}

Over the past few years, HBPs have received much attention as modifiers of epoxy systems to improve the mechanical properties, reduce the shrinkage on curing [51] and increase the reworkability [31], if the structures are conveniently selected $[45,91]$.

One of the first HBPs used as modifier for epoxy resins was an aliphatic hyperbranched polyester based on 2,2-bis(hydroxymethyl)propionic acid (BHMPA) [92]. This polymer was produced and commercialized by Perstorp as Boltorn HX (where X can be 20, 30 or 40 related with the degree of polymerization). There are several published papers on the use of Boltorn as a modifier in different epoxy thermosetting systems. Ratna etal. [93] used Boltorn H30 as a modifier in epoxy/amine thermosets. The final materials showed globular HBP particles dispersed in the epoxy matrix and the result was a significant improvement of the impact strength, approximately twice the value of the neat material, when a high concentration of HBP was used. However, Yang etal. [94] obtained homogeneous materials in epoxy/anhydride systems and the improvement in impact strength was around $25 \%$ over the pure epoxy/anhydride matrix by the addition of HBP as a modifier. This could be explained by the formation of particles in the first case and a homogeneous material in the second due to the different chemistry implied in the curing process.

Different modifications of Boltorn-like polymers have been described in the field of thermosets. Varley and Tian [95] reported the use of an epoxidized Boltorn as a modifier of epoxy/anhydride systems. The addition of HBP had a minimal effect on the viscosity of the mixture. Furthermore, the modified materials showed excellent improvements in toughness. A $100 \%$ increase in fracture toughness was achieved by the presence of a $20 \% \mathrm{wt}$ of HBP in the epoxy network.

The effect of DB of HBP in the improvement of epoxy materials cured by the cationic initiator was studied [96]. In these systems, the viscosity of the formulation was lower on increasing the DB of the modifier, which confirms the advantages in the rheological behavior of HBP-modified formulations. On increasing the DB, the $T_{g}$ was increased and the storage moduli in the rubbery state followed the same trend. The addition of HBP to the formulation led to a reduction of the global shrinkage on the curing process, which increased with the proportion of modifier and DB. Because of the aromatic poly(ester) nature of these HBPs, the thermal stability increased, but the chemical reworkability in the basic solution improved. The high thermal stability is due to the fact that aromatic ester groups cannot be broken by $\beta$-elimination processes because of the absence of hydrogen in the $\beta$-position [31]. This study put in evidence the validity of the dendritic characteristics in the improvement of epoxy thermosets.

Boltorn polyesters have also been used to control the shrinkage in the cationic polymerization of DGEBA using hydroxyl-terminated HBPs [51]. The reduction in contraction during curing was observed because inter- 
molecular and intramolecular H-bond interactions decreased and the free volume increased when HBP reacts and gets incorporated into the network.

The large number of reactive sites present in the HBPs structure allows the possibility of changing their solubility in the epoxy matrix by the attachment of polar or nonpolar units to the end groups [97]. As a result, optimal shell chemistry design of the HBP could be achieved, which permits one to obtain homogeneous or nano- and microstructured thermosetting materials [91]. Moreover, by tailoring their chemistry, it is possible to reach suitable mechanical properties for inducing the most efficient toughening mechanism [98]. Flores et al. $[99,100]$ reported the use of partially modified Boltorn-type polyesters and hyperbranched poly(glycidol) with 10-undecenoyl moieties as modifiers in DGEBA thermosets. The materials obtained resulted in a significant increase in impact strength, since the use of partially modified HBP led to phase-separated materials with particle sizes on the nanometric or micrometric scale with good interaction between particles and matrix because of partial covalent bonding. Both structural facts led to a cavitation mechanism of toughness enhancement. This enhancement was possible without affecting the thermal stability, thermomechanical characteristics or processability of the formulations.

Other HBPs as poly(ester-amide) and poly(amino-ester) have been used as modifiers for epoxy resins, leading to improvements in shrinkage, degradability or mechanical properties [52, 101]-[103]. The effect of molecular weight of different hyperbranched poly(ester-amide)s before shrinkage was investigated and a progressive decrease of global shrinkage was observed on increasing the proportion of HBP and in the higher molecular weight [101].

In addition to HBPs, multiarm SPs can also be considered as a new class of modifiers for epoxy resins. Meng etal. [42] obtained nanostructured diglycidylether of bisphenol A thermosets using core-crosslinked stars based on poly(styrene) core with poly(ethyleneoxide) or poly(styrene)-b-poly(ethyleneoxide) arms. $T_{\mathrm{g}} \mathrm{s}$ values of the epoxy thermosets containing the modifiers were clearly improved. The mechanical properties (Young's modulus, impact strength and microhardness) showed a maximum value when $10 \%$ wt of the modifier was added to the formulation.

It has been reported that multiarm stars with poly( $\varepsilon$-caprolactone) (PCL) arms and different cores were used as epoxy thermoset modifiers [90, 102,104]. The addition of these polymers led to homogeneous materials with a more tough fracture while reducing the shrinkage on curing without compromising the thermomechanical properties. Multiarm SPs with poly(styrene) and poly(methyl methacrylate) arms were also used as modifiers in epoxy systems obtaining phase-separated materials or nanograined morphologies [105, 106]. The impact strength was improved in the material with the highest content of modifier. Chemically reworkable epoxy coatings by the addition of these star topologies were also prepared [32]. An important characteristic of these modifiers is the low viscosity of the formulation. It could be demonstrated that on increasing the number of arms and shortening them, the viscosity was lower [107].

Miktoarm SPs were also synthesized with a hyperbranched polyester core and poly(ethylene glycol) arms or poly(ethylene glycol)/PCL arms [108]. The resulting materials, due to the amphiphilic character of the multiarm star, showed phase-separated morphologies with nanosized particles and a significant improvement on impact strength. The best improvement was obtained by using the miktoarm containing poly(ethylene glycol)/PCL arms. Due to the hydrophilic/hydrophobic character, this modifier demonstrated a high self-assembly tendency, responsible for the improvement.

\section{HBPs and multiarm SPs from PEI}

The common terminal groups of HBPs are hydroxyl moieties. Through them, numerous functional components can be introduced into the HBP structure. However, amine-terminated HBPs are also interesting and have been scarcely explored. Hyperbranched PEI presents a high content of amino groups and is very attractive for several industrial applications [109]. One of the most important features of PEI macromolecules is their availability at industrial scale and low cost.

Nowadays, there are many companies selling HBPs, which are used in many industrial applications. Among them, BASF commercializes a family of HBPs with the name of Lupasol that consists of hyperbranched poly(ethylenimine) (PEI) [110]. It should be said that firstly PEI was commercialized under the name Polymin [111]. PEI, also called poly(aziridine), is a polymer with a repeating unit composed of an amino group and an ethylene spacer (Figure 22). 


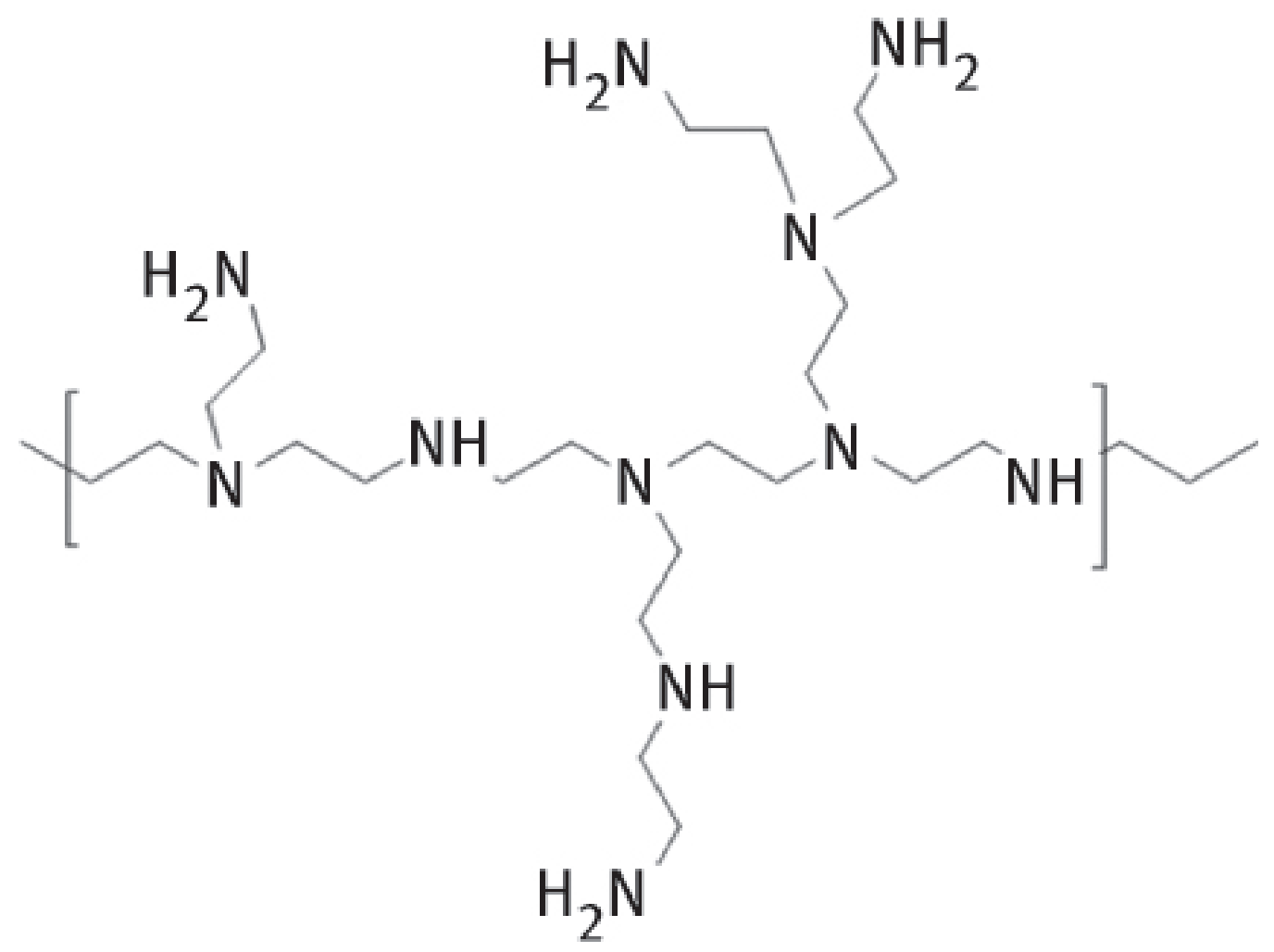

Figure 22: Chemical structure of hyperbranched poly(ethyleneimine)

The industrial production of ethyleneimine and PEI began in Germany about 1938, when I.G. Farbenindustrie (founded as a merger of BASF, Bayer, Agfa, Hoechst, Chemische Fabrik Griesheim-Elektron and Chemische Fabrik) built and operated a plant in Ludwigshafen. In 1951, the company was split into its original constituent companies. The four largest companies (BASF, Bayer, Agfa and Hoechst) quickly bought the smaller ones.

Hyperbranched PEIs are produced in a large scale by self-condensing ROP. In this methodology, a heterocyclic monomer is used and a cationic or anionic mechanism is applied. Lupasol products are obtained through cationic polymerization of the ethyleneimine monomer (aziridine) by a wide variety of acidic reagents and quaternizing agents [112]. The polymerization is terminated by reaction with water. Under these conditions, branched-chain structures are formed as is shown in Figure 23. The DB is dependent upon reaction conditions such as catalyst and ethyleneimine concentration. PEI dendrimers were also prepared [113].
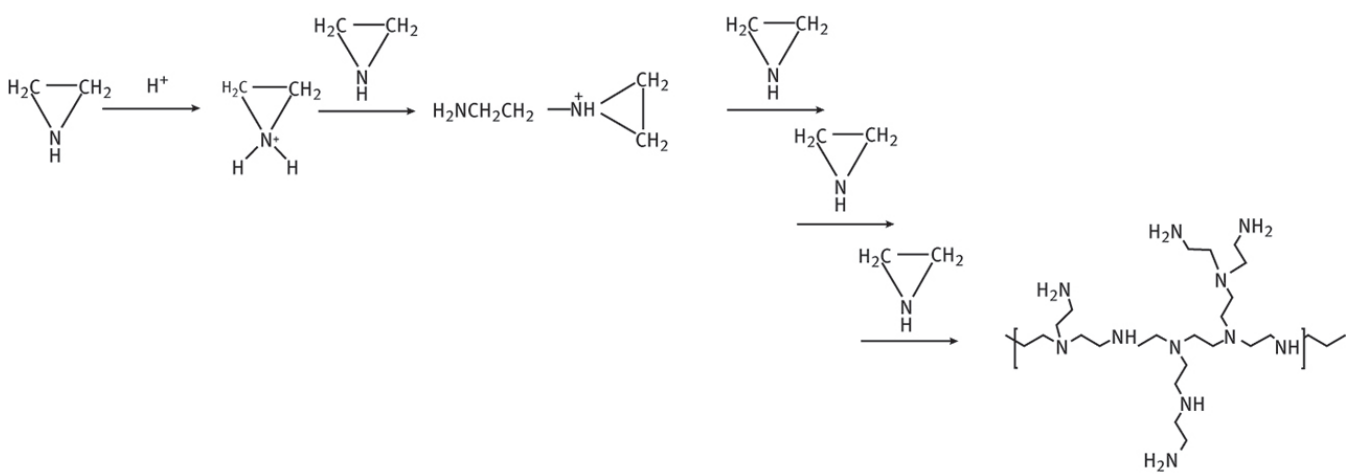

Figure 23: Synthesis of poly(ethyleneimine) from aziridine monomer

The Lupasol product range is extensive. Water-free products and aqueous solutions are commercially available and applied to a huge variety of materials providing advantages and new properties. PEI was first described as an agent for producing wet-strength papers, being usable in neutral or alkaline systems, a significant departure from the acid-requiring urea-formaldehyde resins that were extensively used. However, the use as additive in this field has been diminished, with the exception of certain special papers, by the arrival of new wet-strength agents that can perform this function more advantageously [114]. In addition, PEI has been used for the preparation of cationically active papers from chromatography and electrophoresis [115]. 
In the textile industry, PEI improves the dye fixation [116], hydrophilicity [117] and flame-proofing of cotton [118], among others. Moreover, the unique properties of PEI make it useful in many applications (plastics, metals, etc.) [119] and can be used as flocculating agents, disinfectants, etc. [120]. In coating technology, the addition of PEI makes coatings and adhesives stick better to porous and nonporous surfaces [121]. In the biomedical field, PEI has attracted an increasing interest because of its potential application in gene delivery [122].

By modification of PEI, the application range can be further expanded. Amidation with acids, alkoxylation, alkylation and carboxylation has been performed, leading to PEI-modified structures used as $\mathrm{CO}_{2}$ cells [123, 124], detectors with specific recognition elements [125, 126], drug delivery [127] or nano-carriers [128], among others.

Recently, Appelhans et.al. introduced mono- and oligosaccharide units on the PEI surface by reductive amidation or N-carboxyanhydride polymerization $[129,130]$. These defined novel oligosaccharide architectures on dendritic polymer surfaces have been studied as nano-sized carrier systems for gene delivery $[131,132]$ or metal nanoparticles [133, 134].

PEI shows high potential for the preparation of core-shell-type SPs and it has been used as a macroinitiator since amine groups can react easily with many of the reactive groups. Bauman etal. [135] grafted linear polyamide-12 into PEI by two different pathways, through transamidation of linear PA12 in the presence of PEI core or by ROP of laurolactam.

Starting from PEI as the core, SPs have been synthesized polymerizing $\varepsilon$-caprolactone (CL) [136]. These polymers were used as unimolecular micellar nanocapsules for accommodating guest molecules [122, 137]. Following the same methodology, SPs containing a PEI core and poly(lactide) arms were prepared and used as nano-carriers [138].

Unmodified PEI has also been used as a curing agent of the epoxy-amine system. The HBP can be incorporated into the network structure of the thermosets to improve the shape-memory behavior with an enhancement of the thermal-mechanical properties [139, 140].

The reactivity of amino groups in the PEI structure toward acids, isocyanates, acrylates and epoxides allowed one to prepare a series of new structures that can be used in the improvement of epoxy thermosets. The incorporation of different reactive end groups in PEI has opened the possibility of obtaining thermosetting materials by different methodologies. Hybrid organic-inorganic epoxy materials could be prepared by the sol-gel approach from trialkoxysilylated PEI [141, 142] and by using "click chemistry" different thiol click reactions could be performed on conveniently modified PEI, forming copolymeric materials with epoxy networks [143, 144]. The possibility of growing polyester arms from PEI cores by ROP has also been applied to prepare a family of multiarm stars that have been further used in the epoxy thermosets modification [145]-[148].

\section{Modification of hyperbranched PEI with long alkyl chains and its use as modifier in epoxy thermosets}

The toughness of epoxy thermosets is an important characteristic in many applications and many efforts have been made to date in order to improve it. The addition of conventional toughening modifiers such as rubbers and high-performance thermoplastics is the main strategy that has been followed by several authors [149, 150]. However, these additives compromise the modulus and the thermomechanical characteristics of the thermosets, which restrict their range of application. In order to overcome these limitations, HBPs have been proposed as reactive modifiers, leading to a significant improvement of this property without negatively affecting the thermomechanical characteristics [151].

The modification of different epoxy systems using commercially available HBPs has been reported [52, 103, $152,153]$. An increase in impact strength was achieved without sacrificing the thermal and thermomechanical properties. The enhancement of toughness could be explained by the flexible structures from the HBPs, which increase the capability of the epoxy matrix to undergo plastic deformation. The high density of hydroxylic groups that can react with some curing agents allows the covalent linkage of the HBP to the epoxy matrix, resulting in homogenous materials.

PEI could be considered as an alternative to hyperbranched polyesters for the modification of DGEBA since the presence of a high content of amines can increase the compatibility between the HBP and the epoxy matrix. Santiago etal. reported the use of hyperbranched PEIs as curing agent and studied in detail the curing kinetics in comparison with a linear aliphatic triamine [139]. Moreover, as epoxy modifier, the effect of the molecular weight of the PEI on the thermal, dynamomechanical and mechanical properties of 1-MI/epoxy-based materials was examined [154]. Recently, taking into account the results obtained using the PEI as a crosslinking agent, the shape-memory behavior has been studied [140]. High values of shape-recovery rate were achieved depending on the crosslinking density. However, amines are very reactive at room temperature with epoxy resins, 
leading to a short pot-life. Therefore, the reduction of the amino reactive groups in the structure is sometimes needed. The easy modification of the amino reactive groups allows one to obtain PEI-modified polymers with many different groups in order to make them suitable for different applications.

It is known that impact resistance is determined by the morphology formed during the curing process. The addition of a modifier that can undergo phase separation during curing is an alternative approach for toughening thermoset polymers [155]. An important method to produce phase-separated thermosets is CIPS. CIPS generally proceeds from an initially homogeneous solution via liquid-liquid phase separation to yield a regular phase-separated morphology in the course of reaction. The increase in the molecular weight of the polymer with the curing reaction results in a decrease in the entropy of the system. To date, there are several reviews on the preparation of micro/nanostructured thermosetting polymers by means of the CIPS methodology [41, 156].

HBPs offer the potential for tailoring their compatibility with epoxy resins through the conversion of their end-groups. The introduction of nonpolar moieties reduces the polarity of HBPs with a consequent decrease in their miscibility with epoxies leading to phase-separated materials by the CIPS methodology. On this base, the modification of HBPs using long aliphatic chains has been reported [157]. Flores etal. prepared a series of partially modified Boltorn $\mathrm{H} 30$ by the acylation process with 10-undecenoyl chloride [99]. Their addition to epoxy/anhydride formulations led to a great increase in the impact strength (more than $400 \%$ ) compared with the neat material. Following the same approach, different modifications of hyperbranched poly(glycidol) were performed and the epoxy thermosets prepared showed a significant increase in impact strength (greater than $200 \%$ ) with respect to the unmodified material [100]. In both cases, the enhancement in impact strength was achieved by the formation of microphase-separated particles by CIPS with a good interaction with the epoxy matrix due to the covalent linkage of the remaining OH groups of HBPs with the curing agent.

The preparation and characterization of PEI derivatives by the amidation process have been followed by several authors [158]-[161]. For example, amidation with fatty acids leads to pigment dispersants for nonpolar solvents [162] due to the decrease in the polar character by the reduction of the amine content. PEIs modified with alkanoic acids with different alkyl chains were used as macromolecular antioxidants [163].

The reactive amines present in the PEI structure can be modified by the amidation procedure, since amines can react with acyl chlorides and acids. To form amide bonds by using acyl chlorides, an additional base is usually required to trap the formed $\mathrm{HCl}$ and to avoid the conversion of the amine into its unreactive $\mathrm{HCl}$ salt and normally $4-(\mathrm{N}, \mathrm{N}$-dimethylamino)pyridine is added [164]. Taking this into account, the modification of PEI by this procedure is limited by the presence of a high quantity of amines, which can be protonated, which makes the purification process difficult. As an alternative, N,N-carbonyldiimidazole (CDI) and dicyclohexyl carbodiimide (DCC) are frequently used for amide bond formation since they do not need an additional base [164]. CDI is the most commonly used reagent for the synthesis of amides from carboxylic acids and amines through the acyl imidazole intermediate (Figure 24) due to the mild conditions under which it can be used, its low cost and the formation of innocuous by-products $\left(\mathrm{CO}_{2}\right.$ and imidazoles).

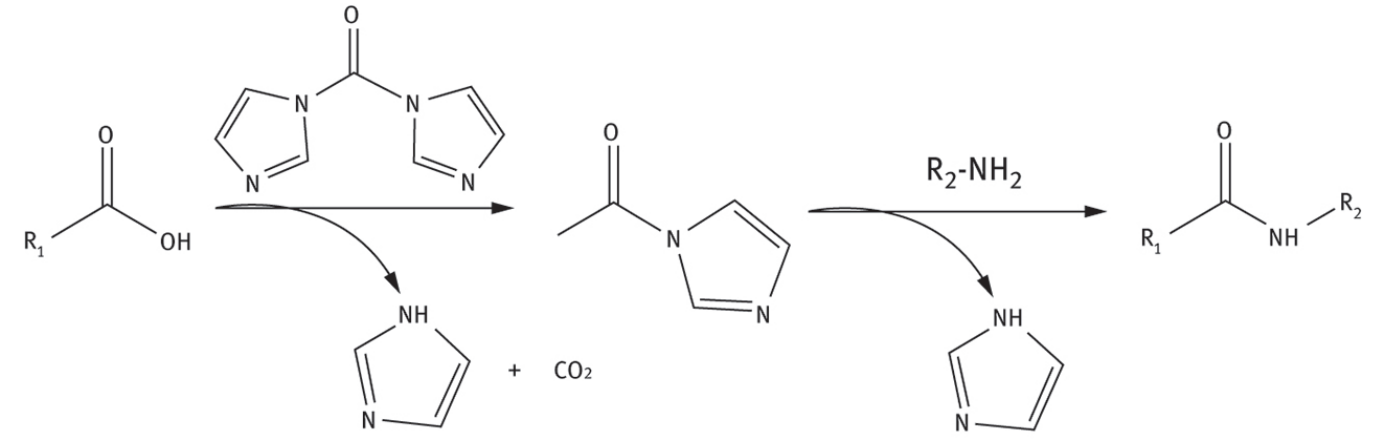

Figure 24: Synthetic procedure of CDI mediated amide formation

The synthetic process is carried out in one pot and two steps: first, the activation of 10-undecenoic acid by reaction with CDI and then the nucleophilic substitution of imidazole group in the CDI derivative by amines of the PEI structure. On changing the proportion of CDI and 10-undecenoic acid to $\mathrm{NH}$ reactive groups, different modification percentages could be obtained [165]. 


\section{Synthesis of multiarm SPs by ROP and their use as modifiers in epoxy thermosets}

SPs are characterized as the simplest case of branched species where all chains of a given macromolecule are connected to a core. The preparation methods and properties of star-branched polymers were examined in detail several years back [84].

Commonly, SPs have been widely used as well-defined nanoparticles for applications in nanomedicine, catalysis, drug and gene delivery, among others [166, 167]. Different functional cores can be used to synthesize multiarm SPs $[168,169]$ and the arms can be obtained using different synthetic methods [170, 171]. The possibility of modifying the structure by the conjugation of different segments to their end functional groups is an advantage to determine the good host-guest properties. Moreover, star-like topologies have attracted considerable interest as toughness modifiers of thermally cured epoxy thermosets because of their unusual physical and rheological properties [42]. The properties of the final materials are related to the SPs structure, the amount of end groups and the molecular weight and length of the arms.

The use of SPs as modifiers in epoxy resins has been explored. Different multiarm SPs were synthesized using poly(glycidol) [104] and poly(styrene) [90] as a macroinitiator and PCL arms and the use of these star-like structures has been demonstrated to be suitable to modify epoxy resins due to their potential as toughening agents. They also showed the capacity to improve other characteristics, without negatively affecting the curing and processability as well as the final thermomechanical properties of the materials.

Generally, SPs can be prepared by "core-first" and "arm-first" methodologies. In the first method, the polymerization of the monomer for the growth of arms is conducted from either a well-defined initiator with a known number of initiating groups or a less-defined multifunctional macromolecule or HBP (Figure 25) [172].
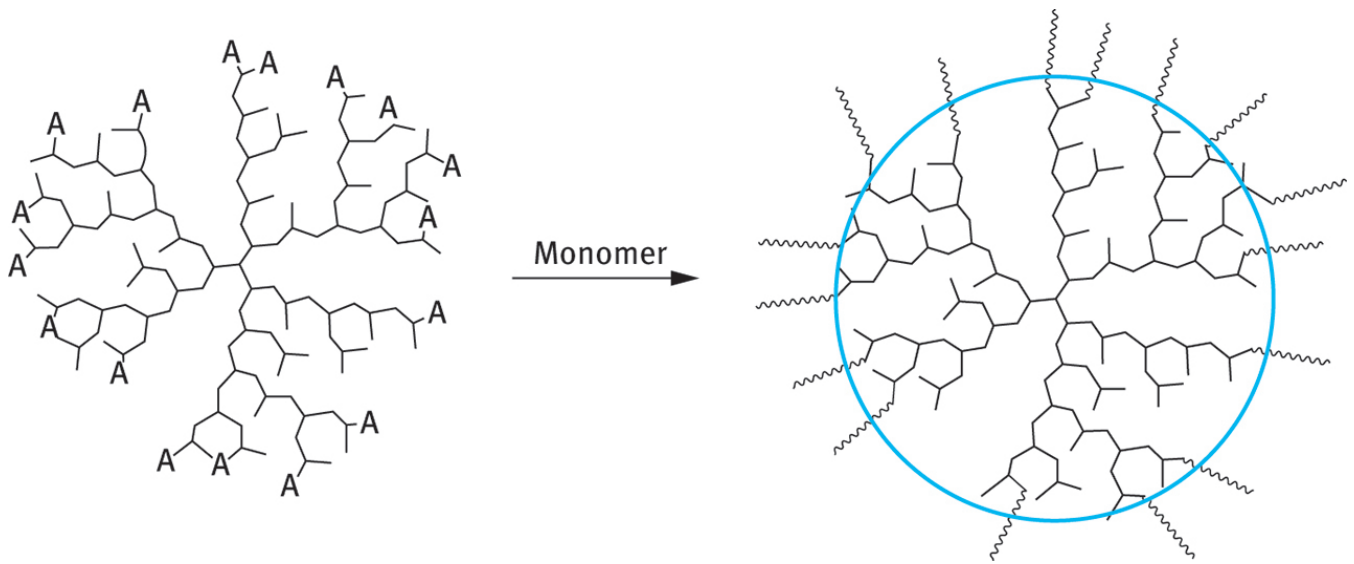

Figure 25: Synthesis of a muktiarm star polymer by the core-first methodology

In the arm-first synthesis (Figure 26), two different approaches are possible: one is where a linear polymer, previously synthesized, with a reactive chain end is directly attached to a multifunctional core (A). The other is the direct copolymerization of a macromonomer with a di- or multifunctional monomer in the presence of an initiator (B) [84]. 
A)
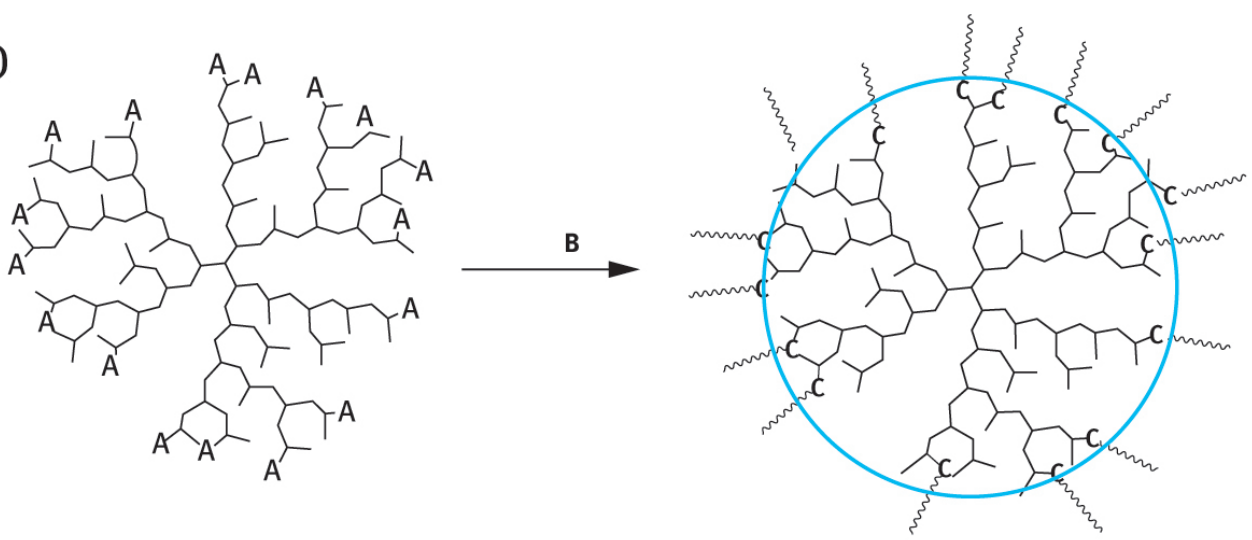

B)

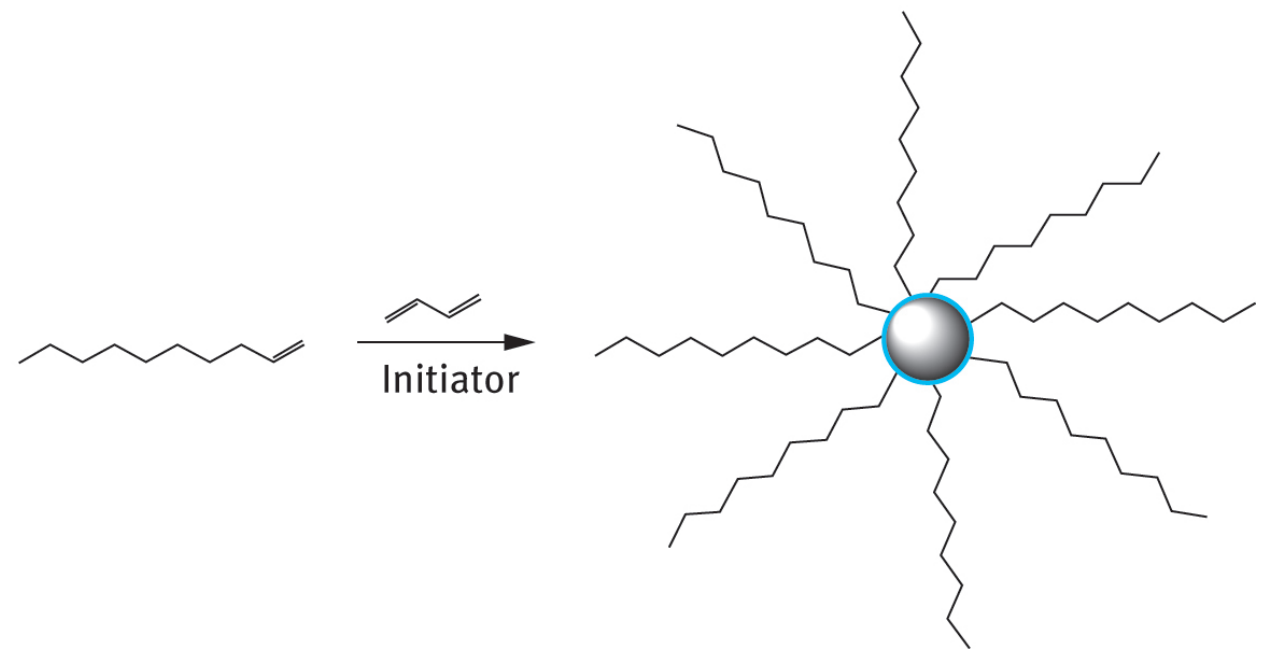

Figure 26: Synthesis of multiarm star polymers by arm-first methodology

In the core-first methodology, the arm length can be tailored by the ratio of active sites to the amount of added monomer obtaining well-defined SPs with a known number of arms. High yields are achieved with only simple purification methods compared with the arm-first method in which the purification processes are much more complex since the impurities consist of polymers that have not been attached to the star structure. Moreover, the number of arms in "arm-first" methodology is not always well-controlled. Despite the approach used, obtaining SP with a high number of arms is a tough task since a macroinitiator is needed (i. e. HBP) and the molecular weight of the arms can be only determined by indirect methods. In most of the core-first syntheses, HBPs like polyesters, polyethers or PEI have been used as macroinitiator [173]-[175].

To date, well-defined stars have been prepared through the ROP of lactide (LA) and CL using polyhydroxyl compounds as co-initiators $[174,176]$. ROP processes, which take place by a living polymerization, provide sufficient polymerization control, producing polymers of the expected molar masses and leading to the desired end-groups [177]. The mechanism allows preparing defined arms in the SPs structures. It has been shown that LA and CL can be polymerized in a controlled manner using Sn-based catalysts in combination with initiating hydroxyl or amine groups. However, references devoted to SPs prepared through the PEI-initiated ROP of LA and CL were scarce [136, 138].

The polymerization mechanism of CL and LA co-initiated with amines involves several steps to obtain the desired products [178]. The reaction of PEI with CL is preceded by the carboxylate-imine groups exchange at the tin atom in $\mathrm{Sn}(\mathrm{Oct})_{2}$, accompanied by the octanoic acid $(\mathrm{OctH})$ release (Figure 27).

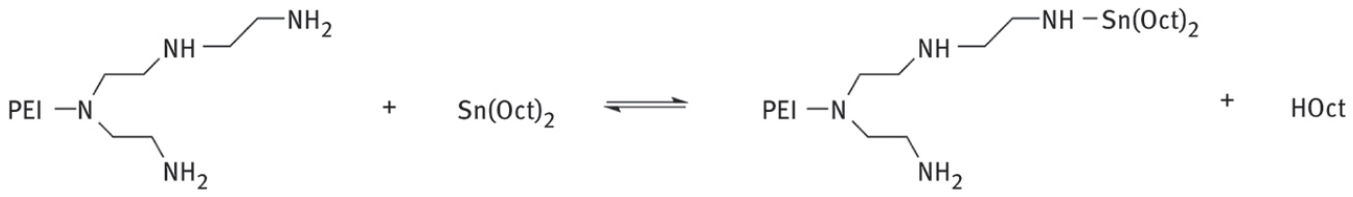

Figure 27: Activation of the macroinititor (PEI) using $\mathrm{Sn}(\mathrm{Oct})_{2}$

The polymerization is followed by CL monomer insertion, forming a new tin(II)-alkoxide specie (Figure 28.a) initiating the propagation step (Scheme 20.b). 

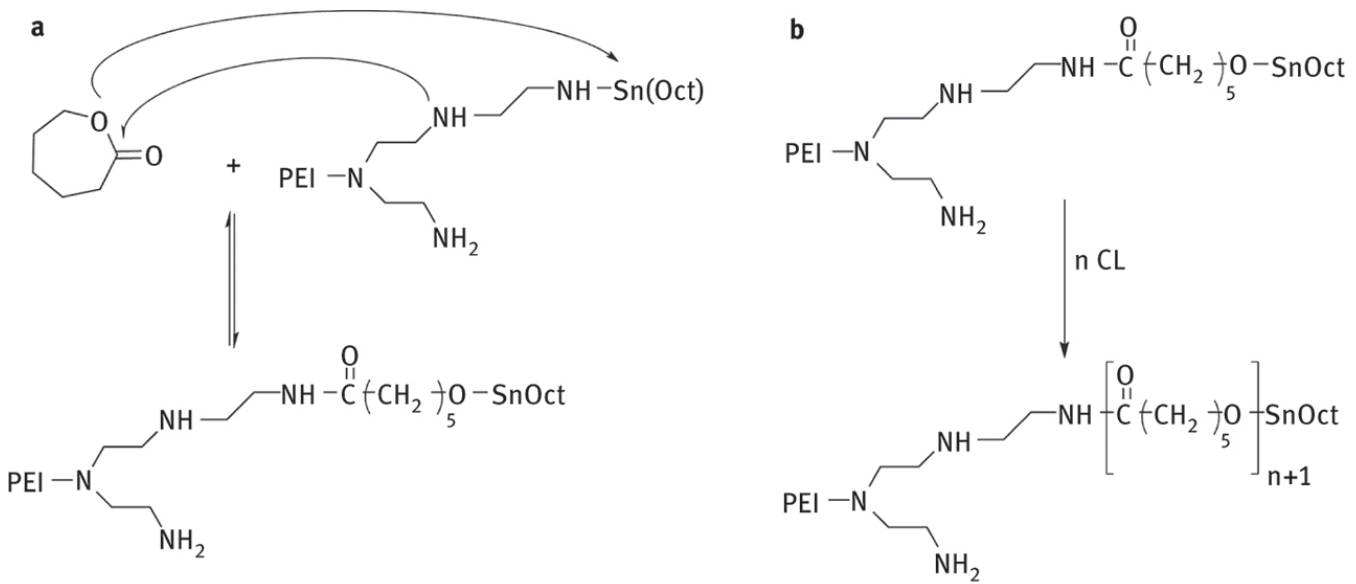

Figure 28: Initiation (a) and propagation (b) of the polymerization reaction

Finally, the exchange reaction with OctH results in the final product and the $\mathrm{Sn}(\mathrm{Oct})_{2}$ is recovered again (Figure 29).
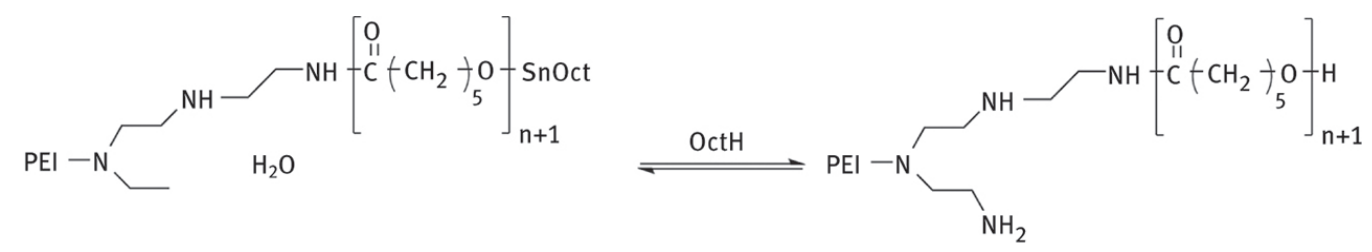

Figure 29: Termination step

By this mechanism, different degrees of polymerization in the arms can be achieved taking into account the ratio of CL and LA to the reactive amine groups. The different structures of repetitive units in the arms can tailor the characteristics of the SPs modifiers [145, 146].

PCL is a hydrophobic, semicrystalline polyester with a high chain flexibility, which is miscible in most epoxy systems [179]. The use of PCL to modify epoxy resins appears to be a good choice due to the presence of $\mathrm{OH}$ groups as chain end that could be covalently linked to the epoxy network if the proper curing agent is used. Its flexible structure is capable of promoting crazing and shear yielding, leading to a toughened material [180]. Moreover, the presence of aliphatic esters, which can undergo thermal degradation by a pyrolytic elimination process, allows the reworkability of the modified coating.

In the same manner, the incorporation of poly(lactide) (PLA) in SPs can enhance the final mechanical properties of the thermosetting materials and a higher thermal reworkability is expected by the lower thermal stability of the secondary ester groups of PLA compared to esters of the primary alkyl groups of PCL [181].

It is known that the formation of micro- or nanostructures improves the overall properties of thermosetting materials [182]. One strategy to reduce the compatibility of SPs and to form well-dispersed SPs microparticles in the final materials is the modification of hydroxyl groups by acetylation to obtain end-capped multiarm SPs $[147,148]$. Following this strategy, impact resistance could be enhanced by $300 \%$ compared to neat DGEBA/anhydride formulations.

\section{Ethoxysilylation of hyperbranched PEI and the use in the preparation of hybrid thermosets}

Demands for epoxy resins are extremely strong because of their wide applications as adhesives, coatings and as advanced composites in aerospace and electronic industries [10]. However, epoxy thermosets have several limitations mainly related to their low mechanical properties and high thermal expansion coefficient (CTE) compared with inorganic materials. Thus, when applied as protective coatings on metal substrates, they are quite fragile and the variation in the temperature leads to a mismatch between the substrate and the coating, leading to the loss of adhesion and to the apparition of cracks. These limitations can be overcome by using inorganic/epoxy materials [183]. Inorganic fillers are the most common additives used in epoxy formulations to improve mechanical properties, such as modulus, strength and scratch resistance [184]. 
These materials can be obtained by different routes: (a) by the addition of preformed nanoparticles or nanoclusters [185] or (b) by the in situ generation of an inorganic phase through a conventional sol-gel process [186]. The in situ sol-gel polymerization of metal precursors in a polymeric (or monomeric) matrix is a better approach before the addition of silica fillers since this makes possible a very fine dispersion of the inorganic phase in the polymeric matrix.

The sol-gel process consists of two different reactions on metal oxide precursors: hydrolysis and condensation, which occur in aqueous solutions, or in the liquid state, or in organic solutions in a highly humid atmosphere, producing polymeric inorganic metal oxide particles. As inorganic precursors, $\mathrm{Si}$ derivatives, $\mathrm{Al}, \mathrm{Ti}, \mathrm{Zr}$, $\mathrm{Sn}$ and V salts can be used [187]. However, Si derivatives are the most used. The formation of silica structures is represented in Figure 30.

\section{Hydrolysis}<smiles>C[Si](C)(C)O[PH2+]O</smiles>

\section{Condensation}

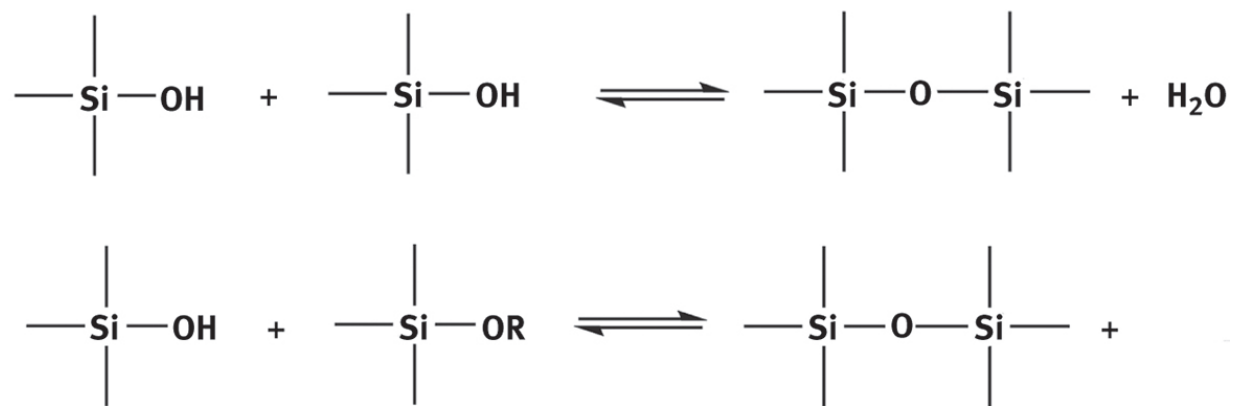

Figure 30: Sol-gel reaction of silicon inorganic precursors

Hydrolysis is a reversible process in which there is the possibility that alcohol attacks the silanol, leading to the formation of an alkoxide. This process is known as re-esterification and is favored at high content of alcohol as the solvent or in the presence of other hydroxylic species [188].

Another reaction that can occur during a sol-gel process is transesterification, which is the reaction of an alcohol with a silylalkoxide with the corresponding formation of a different silylalkoxide (Figure 31).

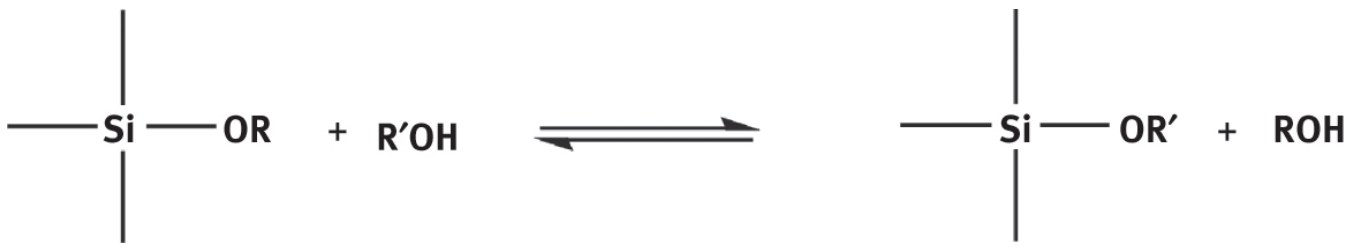

Figure 31: Transesterification reaction

This reaction occurs when the alcohol used as the solvent is different from that formed in the hydrolysis reaction but can also be used to link poly(hydroxylic) compounds to silica structures or to functionalize hydroxylated surfaces.

The sol-gel process is acid or base catalyzed and the silica structure is determined mainly by the catalytic conditions. Thus, acid catalysis favors a faster hydrolysis of the precursor, finally leading to an open weakly branched polymer-like structure. On the contrary, in a basic medium the hydrolysis occurs slower but the polycondensation is faster, producing compact colloidal particles $[189,190]$. In Figure 32the effect of the catalyst in the morphology of the network is depicted. 


\section{$\mathrm{Si}(\mathrm{OR})_{4}$}
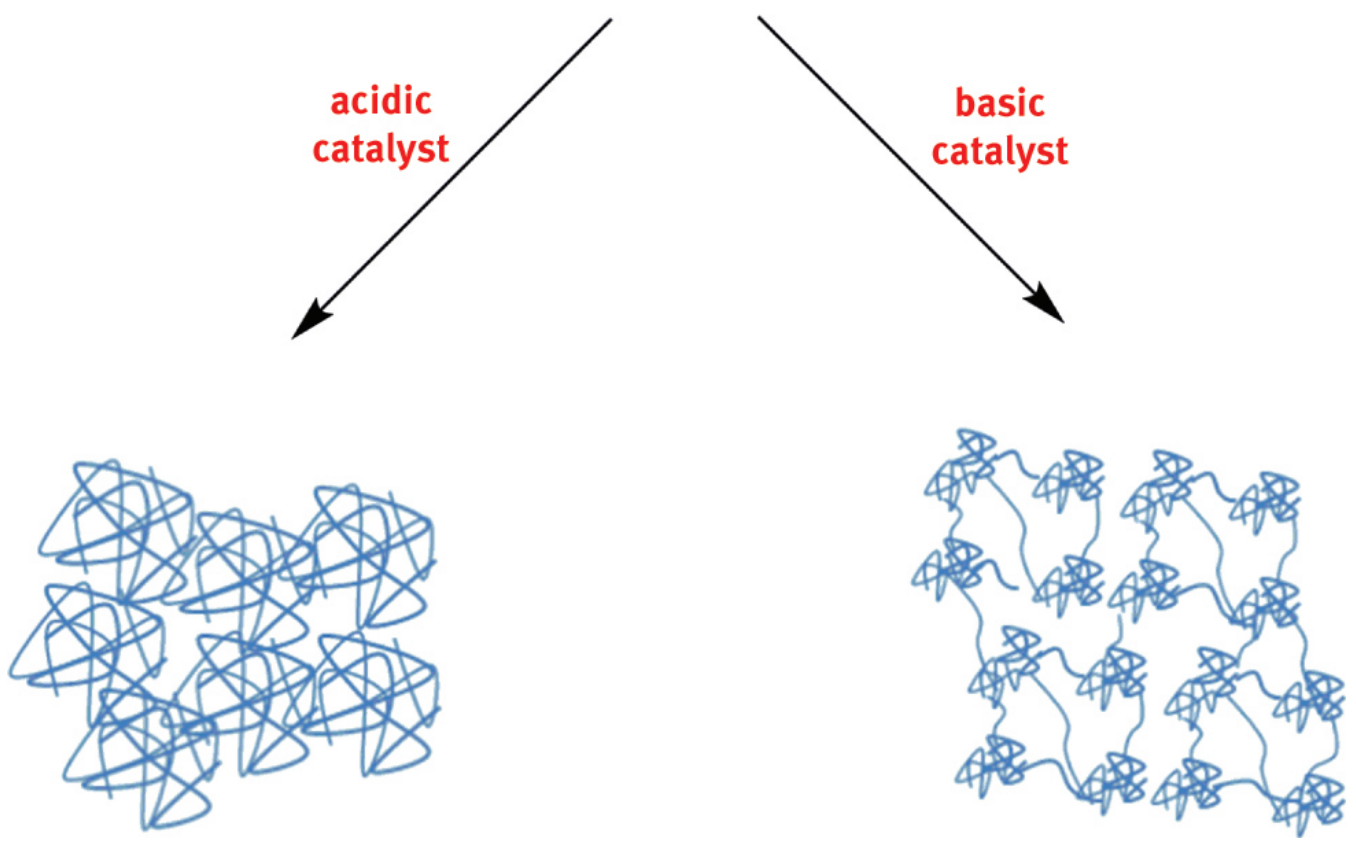

Figure 32: Catalyst influence in the formation of the inorganic network by sol-gel

The formation of the inorganic silica network depends on the condensation reaction of the previously formed silanol structures that leads to new $\mathrm{Si}-\mathrm{O}-\mathrm{Si}$ bonds. Generally, the precursors have three (trialkoxysilane, $\mathrm{T}_{n}$ ) or four (tetraalkoxysilane, $\mathrm{Q}_{n}$ ) hydrolyzable groups. The subscript $n$ indicates the number of silanol groups condensed to siloxane bonds. In Figure 33the chemical structures of silanols and the possible structures produced in the condensation are represented. From [29] Si NMR experiments, it is possible to determine the structural details on the degree of hydrolysis and polycondensation.

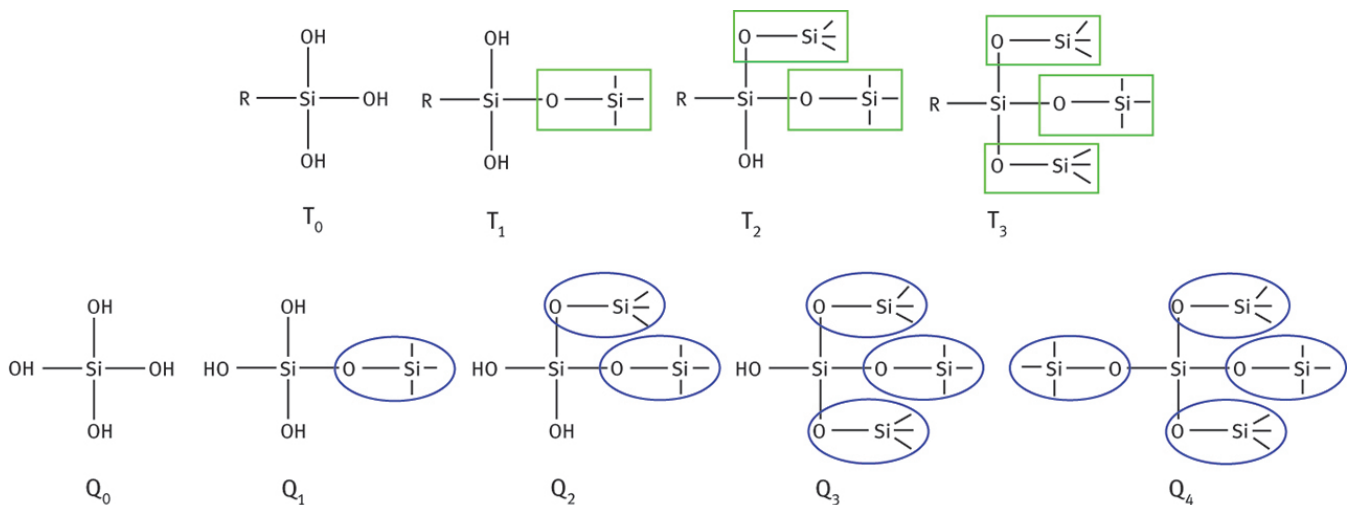

Figure 33: Structure of the possible condensed forms during the sol-gel process

The formation of the inorganic silica structure in epoxy hybrids can take place before or after the curing process. Many sol-gel hybrid materials have been prepared by different curing methodologies [191]. In order to obtain good mechanical properties, the compatibility of organic and inorganic structures by the formation of covalent bonding is an essential condition, and for this reason, the use of coupling agents is needed $[192,193]$. Usually, commercially available trialkoxysilyl compounds with organic reactive groups are applied as coupling agents in epoxy hybrids, with (3-glycidyloxypropyl)trimethoxysilane (GPTMS) being the most widely used [194, 195]. Moreover, the addition of tetraethyl orthosilicate (TEOS) to the formulation containing organoalkoxysilane precursors usually aims to increase the $\mathrm{SiO}_{2}$ content and the size of the particles formed. The organic-inorganic networks can be tailored by combining the addition of TEOS and the type of coupling agent [196], and the size of particles formed is related to the mechanical properties of the final material [197].

The cyclization of alkoxysilanes by intramolecular polycondensation allows one to form polyhedral functional silsesquioxanes (POSS) with random, ladder cage or semi-cage structures. Octasililsesquioxane $\mathrm{T}_{8}$ (Figure 34) has been observed in sol-gel processes starting from trialkoxysilanes under some particular synthetic conditions [198]. 


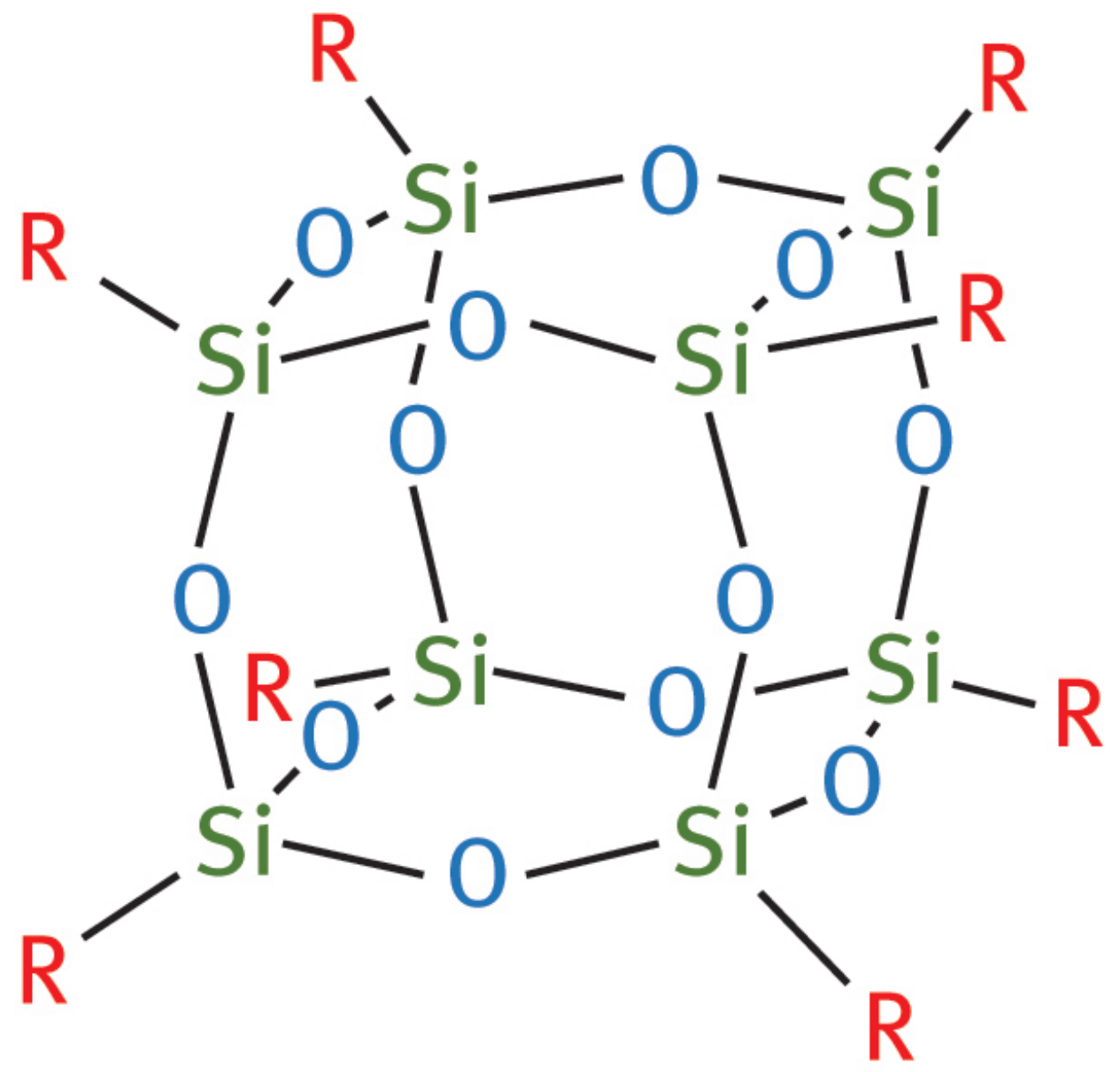

Figure 34: Chemical structure of octameric cage (POSS)

The cage-like structures of POSS can allow the construction of materials with precise control of the nanoarchitecture. For this reason, POSS reagents, monomers and polymers are emerging as a new chemical technology for the nanoreinforced organic-inorganic hybrids and the polymers incorporating POSS are becoming the focus of many studies due to the simplicity in processing and the excellent comprehensive properties of this class of hybrid materials [199, 200].

As has been mentioned before, HBPs are advantageous modifiers to enhance the properties of epoxy thermosets. Taking all of this into account, some authors combined the strategy of the generation of silica particles by the sol-gel procedure with the use of hyperbranched structures to improve some characteristics of thermosetting materials [66, 201, 202].

Since the use of coupling agents is highly advisable, the preparation of multifunctional coupling agents by silylation of the final groups of HBPs can be greatly advantageous to improve epoxy resins by the generation of silica particles by the sol-gel process from the alkoxysilanes at the end groups of the hyperbranched structures [67]. As an alternative, the use of epoxy-terminated HBP as an epoxy component has also been proposed [203].

Taking into account that amino groups are reactive toward isocyanates, the complete modification of PEI with (3-isocyanatopropyl) triethoxysilane was achieved [141, 142]. Triethoxysilylated hyperbranched PEI (PEI$\mathrm{Si}$ ) was used to prepare different hybrid organic-inorganic materials with different silica contents and different inorganic structures. An advantage of the amino groups in the PEI structure is that the amines cannot react with silanol groups in contrast with the hydroxyl groups, avoiding the gelation process during the preparation of the modifier or during storage, which is an undesired side-reaction in $\mathrm{OH}$-terminated hyperbranch. The hybrid materials obtained by the sol-gel process of mixtures of DGEBA and PEI-Si in different proportions showed improved scratch resistance and even self-repairing behavior was observed with the highest proportion of PEI$\mathrm{Si}$. The mechanical characteristics were studied in depth using the depth-sensing indentation methods, which showed the special viscoelastic behavior explaining the self-repairing characteristics [204]. 


\section{Use of modified hyperbranched PEI as a macromonomer in the preparation of thermosets by a two-stage click-chemistry process}

"Click Chemistry" is a term that was introduced by K. B. Sharpless and coworkers in 2001 to describe reactions that are high yielding, wide in scope, stereospecific, simple to perform and can be conducted in easily removable or benign solvents [205]. Sharpless defined click chemistry early on as the generation of complex substances by bringing together smaller units via heteroatoms. This chemistry is not limited to a specific type of reaction and the most commonly used click reactions that have been adapted to fulfill the above criteria are: a) pericyclic reactions commonly the Huisgen type [3+2] cycloadditions and Diels-Alder reaction [206, 207], b) ring-opening of strained molecules such as epoxides, aziridines and aziridiniumions [208], c) non-aldol carbonyl chemistry (involving amines, oximes and hydrazones) [209], d) addition reactions especially thiol-ene/yne chemistry, and Michael additions (Figure 35) [210]. Nowadays, the characteristics of click reactions include a) high yields, b) regiospecificity and stereospecificity, c) insensitivity to oxygen or water, d) mild, solventless (or aqueous) reaction conditions, e) orthogonality with other common organic synthesis reactions and f) amenability to a wide variety of readily available starting compounds [211, 212].

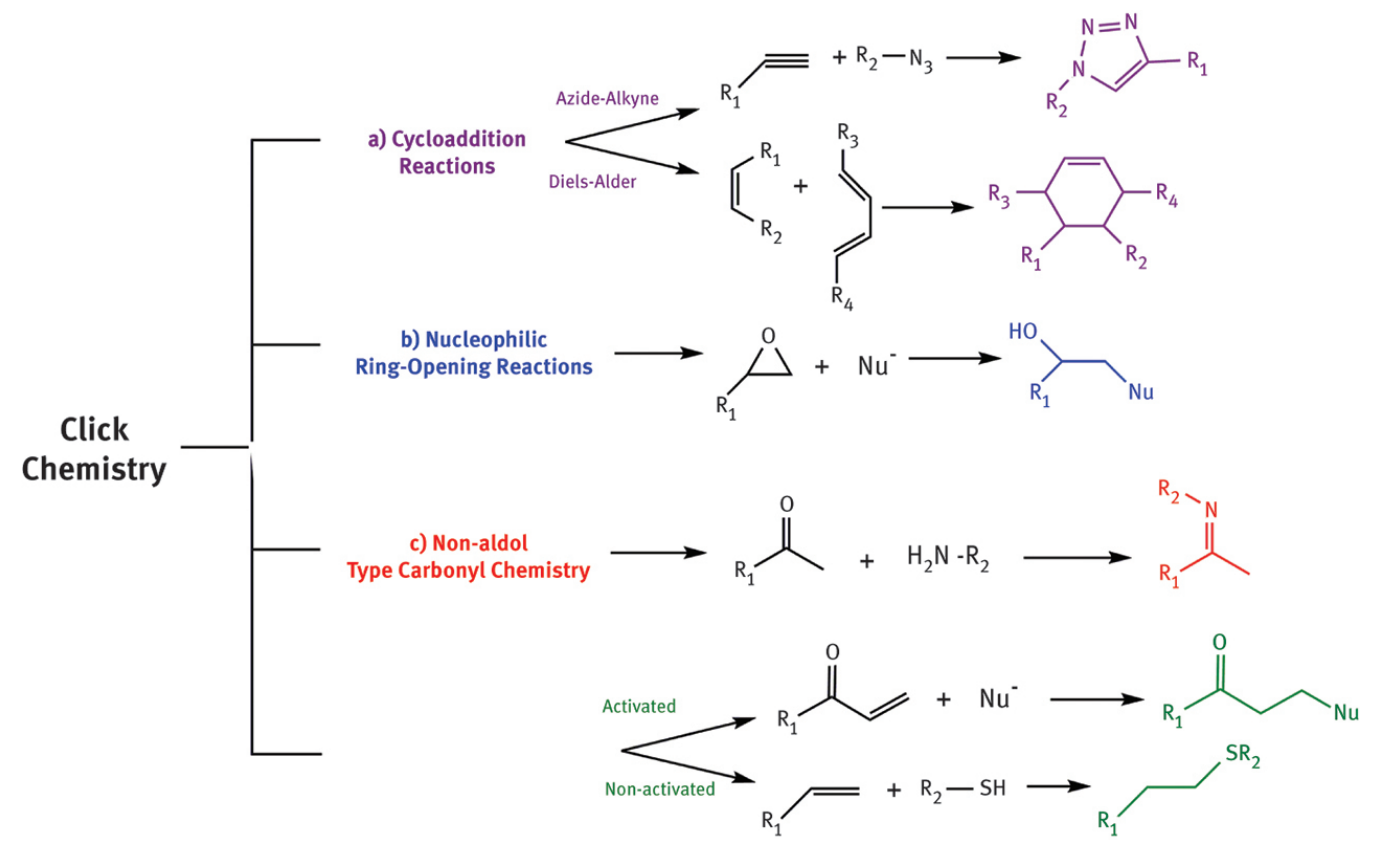

Figure 35: Selection of click reactions

Since the foundation of click chemistry, there has been an explosive growth in publications of this practical and sensible chemical approach, and over the years, the developments in the area of click chemistry have been considerable. As a consequence of its simplicity, this chemistry has a significant impact in applications such as bioconjugation [213], materials science [214] and drug delivery systems [215].

Click chemistry provides powerful and versatile tools for materials synthesis owing to its simplicity, selectivity, efficiency and tolerance of various functional groups. Consequently, a wide range of controlled-architecture materials have been synthesized through various click reactions, including block copolymers, micelles, dendrimers, gels and networks [216, 217].

In material science, the aim is to achieve performance and a set of desired characteristics in the final material and/or device in as simple and effective manner as possible. These performances include specifications on mechanical and physical behavior as well as chemical characteristics. This is related to the goal of click chemistry wherein it argues that the focus of chemical process selection should be directed toward the identification, optimization and simplification of an overall process [205]. For this reason, click chemistry is used in materials development as an effective tool to modify polymers or materials with a variety of functional components and to prepare polymer networks [218]-[220]. Moreover, by different click methodologies stimuli-responsive materials have been synthesized [221] and nanoscale materials have been prepared due to their efficiency and selectivity [222].

Among all the click reactions, thiol chemistry has attracted a great deal of attention due to its efficiency and versatility with numerous thiol reactions [223]. The reactivity of the thiol gives rise to an advantage of the thiol-click reactions in that they proceed, under appropriate conditions, more rapidly than many other click processes in some cases, with the reaction times necessary to achieve high conversions being less than 1-10 s. 
Thiol chemistry can be divided into two categories: the base-catalyzed nucleophilic reactions associated with the thiol-epoxy, thiol-isocyanate and thiol Michael addition reactions and radical-mediated reactions related to the thiol-ene and thiol-yne reactions (Figure 36) [210].

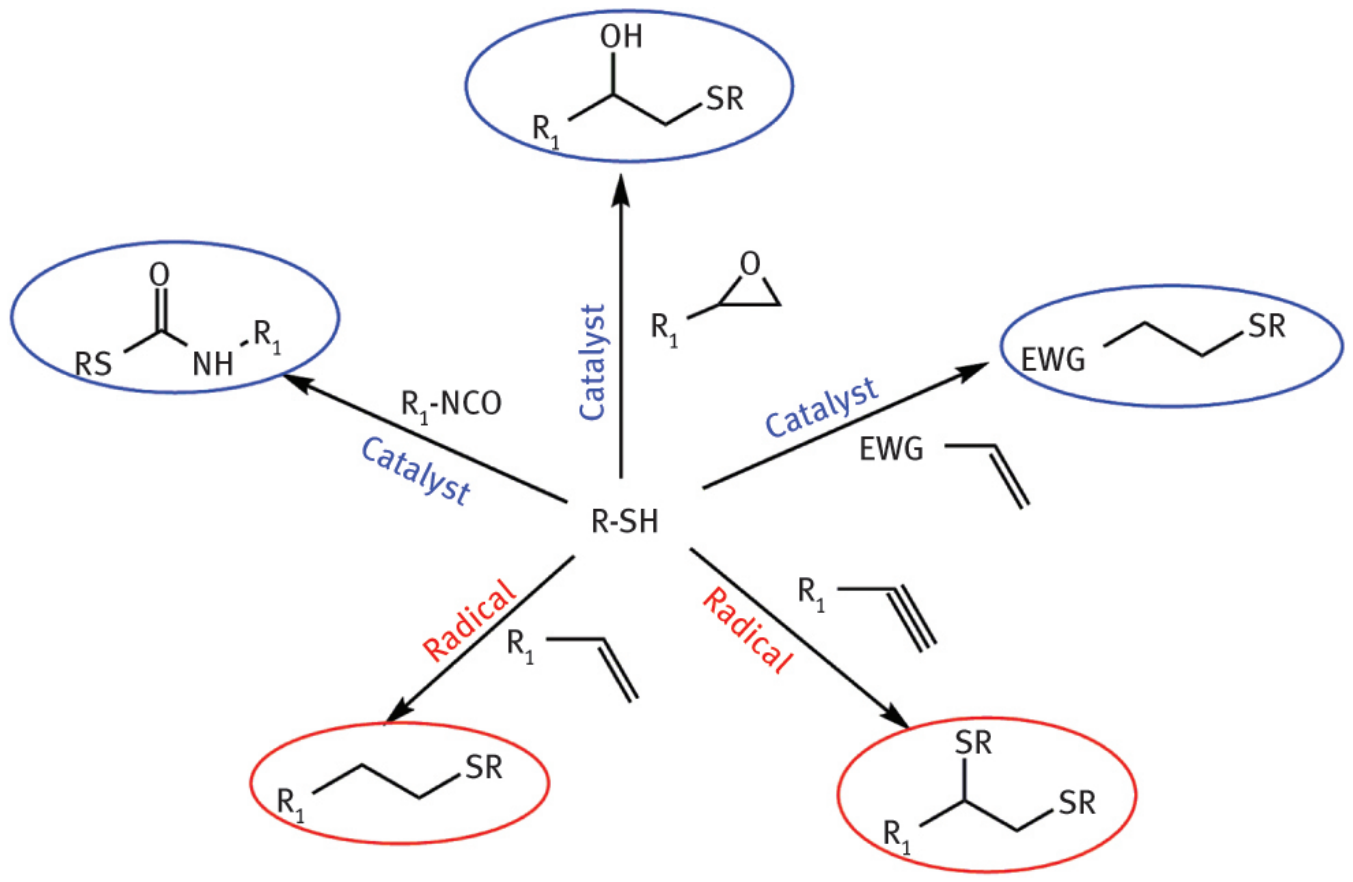

Figure 36: Different thiol-click reactions

The thiol-epoxide reaction has been implemented in many important biosynthetic and biomedical applications [224]. In addition, the ring-opening reaction involving thiols and epoxides is industrially important and involved in the formation of adhesives, high-performance coatings and composites [225].

The basic thiol-epoxy reaction mechanism is a simple nucleophilic ring-opening reaction by the thiolate anion followed by protonation of the alkoxide anion via the quaternary ammonium (Figure 37a) originally formed via reaction of the base catalyst and thiol to generate the initial thiolate or by proton exchange between the formed alkoxide and another thiol (Figure 25). This mechanism was proposed to describe the curing of thiol-epoxy systems catalyzed by bases [226].

a)

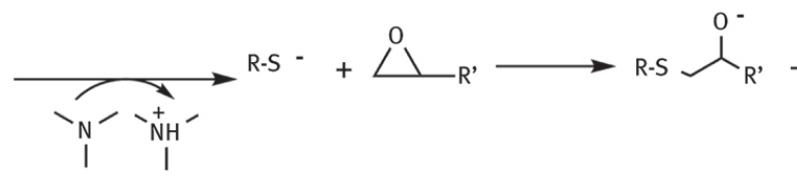

b)

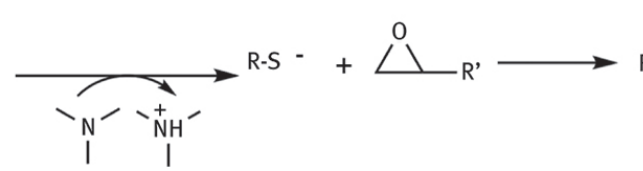<smiles>[R5]CC([2H])C(C)C</smiles>
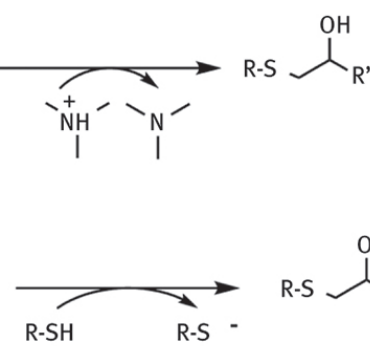

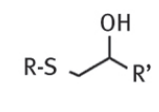

Figure 37: Catalyzed thiol-epoxy ring opening polymerization

However, the low basicity of some tertiary amines that can be used as catalyst for the thiol-epoxy reaction makes the proton exchange leading to the formation of a thiolate anion highly unlikely. An alternative reaction mechanism was recently proposed to model successfully the thiol-epoxy curing catalyzed by a moderately basic tertiary amine [227]. First of all, there is a nucleophilic attack of the tertiary amine on the epoxy ring, with the assistance of a proton donor such as an alcohol to facilitate ring-opening (Figure 37), followed by proton exchange between the thiol and the alkoxide to produce the thiolate anion and a hydroxyl ammonium compound. The thiolate anion propagates the reaction by nucleophilic attack on the epoxy ring and the regeneration of the thiolate anion by proton exchange of the formed alkoxide with another thiol (Figure 37). Usually, this reaction occurs under thermal conditions and the reaction kinetics and the mechanism of the curing process are determined by the base used (Scheme 30) . 
a) Initiation<smiles>[R][SH]S(=O)(=O)CC[13C]1OC1[R]</smiles>

a) Propagation

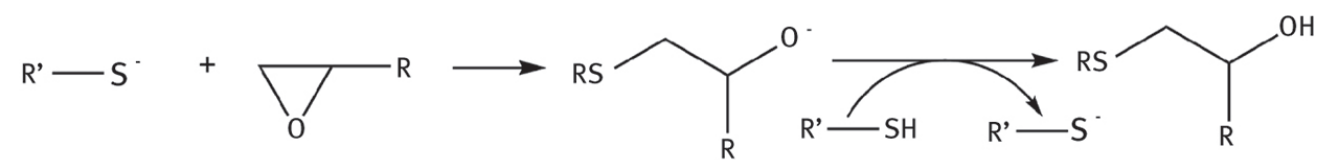

Figure 38: Proposed curing mechanism of thiol-epoxy condensation catalyzed by tertiary amine

Thiol-ene and thiol-yne processes take place by the stoichiometric reaction of alkynes with thiols via a radical step growth mechanism that can be initiated by light, peroxides, thermal initiators or any systems whereby radicals are generated [228]. However, these reactions are commonly initiated photochemically [229]. It should be said that one of the distinct features between thiol-ene and thiol-yne is that in thiol-ene each ene functional group reacts only once with a thiol group whereas in thiol-yne each yne group reacts twice. The use of these thiol reactions ranges from high-performance protective polymer networks to processes that are important in the optical, biomedical, sensing and bioorganic modification fields [230].

Both reactions are efficient tools for the post-polymerization modification of well-defined reactive precursor (co)polymers [231] and for the construction of complex (macro)molecules, such as poly(thioether) dendrimers (Figure 39) [232]. Due to their fast reaction kinetics and high yield, thiol-ene and thiol-yne reactions are highly used for the bioconjugation of polymers, for tissue engineering applications, for the production of degradable polymers and for the preparation of high-quality soft imprint lithographic stamps, among others [230].

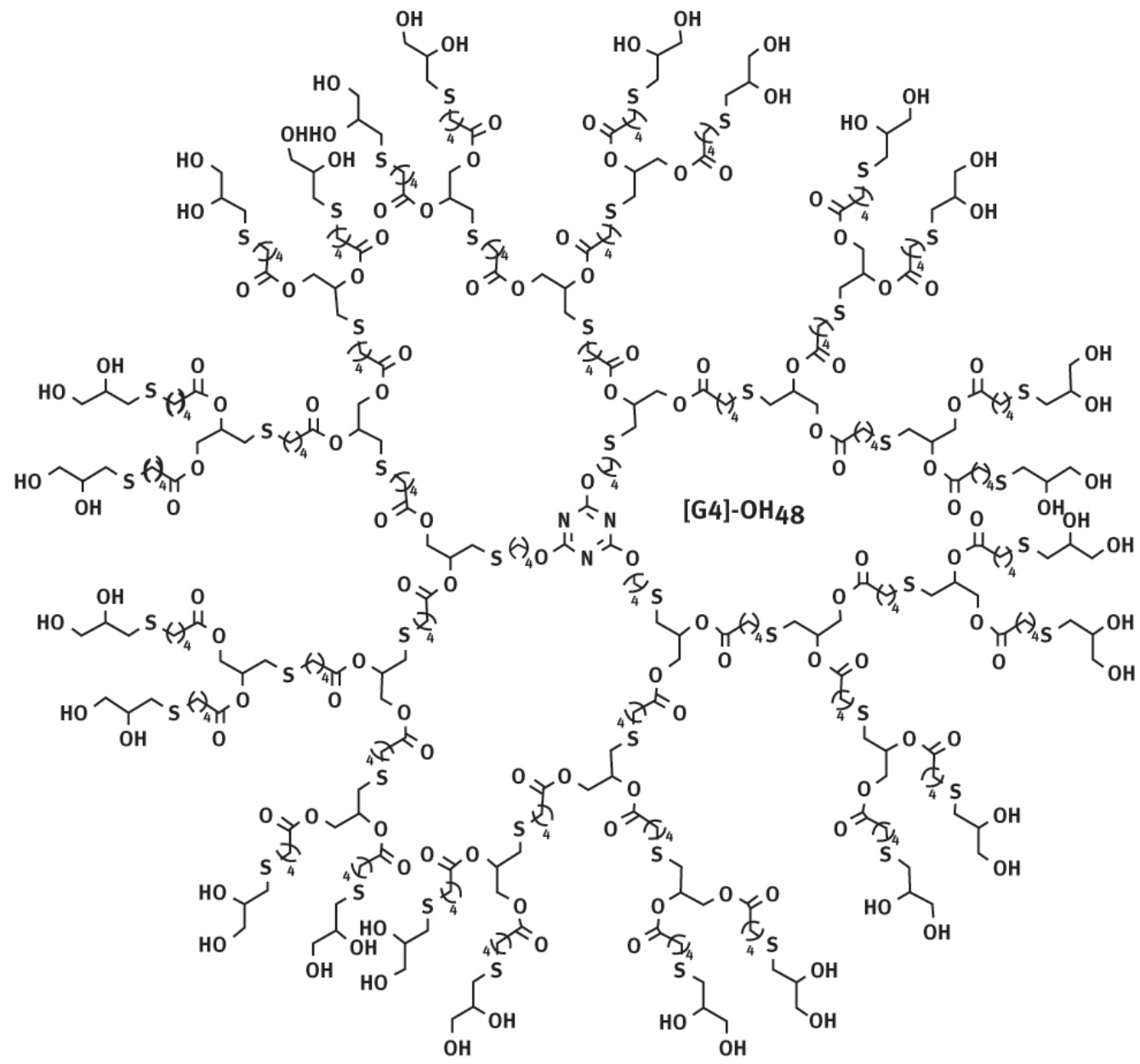


Figure 39: Dendrimer synthesized via radical thiol-ene reaction

In the thermosetting field, thiol-ene and thiol-yne step growth processes are widely used since they allow one to obtain uniform networks with low shrinkage and stress. Moreover, the incorporation of tioether networks permits a higher refractive index than comparable organic networks [233, 234].

Using thiol-ene and thiol-yne methodologies, polysulfide networks have been prepared [235, 236]. However, the materials obtained are limited by their poor mechanical and physical properties due to the flexibility of the thiol monomers. To overcome this disadvantage, several authors combine thiol-ene systems with a network structure derived from thiol-acrylate or thiol-epoxy reaction [237]-[239]. As an alternative, the use of a multifunctional monomer to increase the functionality of the reactive mixture to enhance the thermomechanical characteristics of the final materials has been reported [240].

Taking into account this new alternative, the preparation of allyl and propargyl terminated-hyperbranched PEI as multifunctional macromonomers for thiol-ene and thiol-yne polymerizations was carried out [143, 144]. The nucleophylic attack of amine groups in the PEI structure to the oxirane of allyl or propargyl glycidylethers allow one to reach a quite high degree of modification in mild conditions.

Dual curing is a processing methodology based on the combination of two different and compatible polymerization reactions taking place simultaneously or sequentially, in a well-controlled way. Sequential dualcuring processing makes possible to obtain stable materials after the first curing stage that maintain the ability, upon application of a second stimulus, to activate the second curing stage and complete the processing, leading to a fully cured material with the desired final properties [241].

One goal of click chemistry is the potential of combining multiple click reactions, either performed simultaneously or in tandem, to synthesize complex structures and materials. In recognition of this task, several recent examples of sequential processes involving two thiol reactions, or even more interestingly, thiol-click and alkyne-azide click reactions, are considered. An advantage coming from the first combination is that the thiol component can participate in both processes and therefore the networks arising from thiol-ene and thiolepoxy reactions are covalently interconnected. Another advantage comes from the fact that both thiol-ene and thiol-epoxy reactions are step-wise so that relevant network buildup parameters during both curing stages such as gel point conversion, gel fraction or crosslinking density can be easily calculated using well-established methods [242]. Thus, it is possible to tailor the curing process and the material properties in the intermediate stage and at the end of it in order to fit different processes and material requirements in a flexible way.

Recently, sequential dual curing systems have been reported using different methodologies. Thermosets by two-stage sequential aza-Michael addition and free-radical polymerization of amine-acrylate systems have been prepared. Furthermore, the strategy of combining two thiol-click reactions has been studied [227, 243]. Thermosetting materials were obtained by combining sequential thiol-ene/thiol-epoxy reactions in which the first stage is a radical thiol-ene reaction initiated by a photoinitiator and the second one is a base-catalyzed thiol-epoxy reaction initiated by a tertiary amine [243]. Since the first process is activated by UV-light and the second one is thermal, the aim of this methodology was to reach a dual-curing system with a controlled curing sequence, with no overlapping between both curing reactions, and with sufficient stability in the intermediate stage.

The use of allyl and propargyl-terminated PEIs as macromonomers in thiol-ene and thiol-yne reactions has been studied $[143,144]$. The formation of hybrid networks from the combination of thiol-ene or thiol-yne and thiol-epoxy process allows one to increase the crosslinking density in the final materials obtaining higher $T_{g}$ values compared with polysulfides. Moreover, the use of these macromonomers as modifiers in epoxy thermosetting materials improves the plastic character of the fracture which must enhance the toughness of the materials.

\section{Acknowledgment}

This article is also available in: Tylkowski, Chemical Engineering. De Gruyter (2017), isbn 978-3-11-046828-1.

\section{References}

[1]May CA. Chemistry and technology, 2nd New York: Marcel Dekker, 1988.

[2] Lee H, Neville K. Handbook of epoxy resins. New York: McCraw-Hill, 1967.

[3]Castan P. Swiss Pat. 211,116, 1940.

[4]Ellis B. Chemistry and technology of epoxy resins. London: Blackie Academic \& Professional, 1993.

[5]Pascault ]P, Williams R]]. Epoxy polymers. Weinheim: Wiley VCH. Chapter 12010. 
[6]Pascault ]P, Sautereau H, Verdu ], Williams R]]. Thermosetting polymers. New York: Marcel Dekker. Chapter 2002.

[7]Fisch, W.; Hofmann, W.; Koskikallio, ]. The curing mechanism of epoxy resins. ] Appl Chem 1956, 6, 429-441.

[8]O'Neill LA, Col CP. Chemical and spectroscopic studies of epoxy resin reactions in the surface coating field. ] Appl Chem 1956;6:356-364

[9]Montserrat S, Flaqué C, Calafell M, Andreu G, Málek ]. Influence of the accelerator concentration on the curing reaction of an epoxy-anhydride system. Thermochim Acta. 1995;269:213-229.

[10]Petrie EM. Epoxy adhesive formulations. New York: McGraw-Hill, 2006.

[11]Leukel ], Burchard W, Krüguer RP, Much H, Schulz C. Mechanism of the anionic copolymerization of anhydride-cured epoxies - analyzed by matrix-assisted laser desorption ionization time-of-flight mass spectrometry (MALDI-TOF-MS). Macromol Rapid Commun. 1996;17:359-366.

[12]Fedtke M, Domaratius F. Curing of epoxide resins by anhydrides of dicarboxylic acids: model reactions. Polymer Bull. 1986;15:13-19.

[13] Fernández-Francos X, Rybak A, Sekula R, Ramis X, Serra A. Modification of epoxy-anhydride thermosets using a hyperbranched poly (ester-amide): I. Kinetic study. Polym Int. 2012;61:1710-1725.

[14]Brunelle D]. Ring-opening polymerization: Mechanism, catalysts, structure and utility. Munich: Hanser Publishers, 1993.

[15]Ricciardi F, Romanchick WA, Joullié MM. ] Mechanism of imidazole catalysis in the curing of epoxy resins. Polym Sci: Polym Chem Ed. 1983;21:1475-1490.

[16]Galià M, Serra A, Mantecón A, Cádiz V. Synthesis of diglicydilesters with alicyclic imide structure and their thermal and tertiary amine catalyzed curing. ] Appl Polym Sci. 1995;56:193-200.

[17] Ooi SK, Cook WD, Simon GP, DSC studies of the curing mechanisms and kinetics of DGEBA using imidazole curing agents. Such CH. Polymer. 2000;41:3639-3649.

[18] Rozenberg BA. Kinetics, thermodynamics and mechanism of reactions of epoxy oligomers with amines. Adv Polym Sci. 1986;75:113-165.

[19]Fernández-Francos X, Cook WD, Serra A, Ramis X, Liang CG, Salla JM. Crosslinking of mixtures of DGEBA with 1,6-dioxaspiro $[4,4]$ nonan-2,7-dione initiated by tertiary amines. Part IV. Effect of hydroxyl groups on initiation and curing kinetics. Polymer. 2010;51:26-34.

[20]Chaemy M, Khandani MH. Kinetics of curing reaction of DCEBA with BF3-amin complexes using isothermal DSC technique. Eur Polym ]. 1998;34:477-486.

[21]Castell P, Galià M, Serra A, Salla JM, Ramis X. Study of lanthanide triflates as new curing initiators for DCEBA. Polymer. 2000;41:8465-8474

[22] Mas C, Serra A, Mantecón A, Salla ]M, Ramis X. Study of lanthanide triflates as new curing initiators for cycloaliphatic epoxy resins. Macromol Chem Phys. 2001;202:2554-2564.

[23] García S], Ramis X, Serra A, Suay ]. Addition effect of Erbium (III) trifluoromethanesulfonate in the homopolymerization kinetics of a DCEBA resin. Thermochim Acta. 2006;441:45-52.

[24] García S], Ramis X, Serra A, Suay ]. Cationic crosslinking of solid dgeba resins with ytterbium(III) trifluoromethanesulfonate as initiator. ] Therm Anal Calorim. 2006;83:429-438.

[25] Kubisa P, Penczek S. Cationic activated monomer polymerization of heterocyclic monomers. Prog Polym Sci. 1999;24:1409-1437.

[26] Endo T, Sanda F. Design of latent catalysts and their application to polymer synthesis. Macromol Symp. 1996;107:237-242.

[27]Tomuta AM, Ramis X, Ferrando F, Serra A. The use of dihydrazides as latent curing agents in diglycidyl ether of bisphenol A coatings. Prog Org Coat. 2011;74:59-66.

[28] Hua CZ, Wan S], Wang L, Liu XD, Endo T. Carbonyldiimidazole-accelerated efficient cure of epoxidized soybean oil with dicyandiamide. ] Polym Sci, Part A: Polym Chem. 2014;52:375-382.

[29]Crivello JV, Sangermano M. Visible and long-wavelength photoinitiated cationic polymerization. J Polym Sci, Part A: Polym Chem. 2001;39:343-356.

[30] He D, Susanto H, Modification and stimulation of polymeric membranes. Ulbricht M. Prog Polym Sci. 2009;34:62-98.

[31] Foix D, Erber M, Voit B, Ramis X, Mantecón A, Serra A. New hyperbranched polyester modified DCEBA thermosets with improved chemical reworkability. Polym Degrad Stab. 2010;95:445-452.

[32]Tomuta A, Ramis X, Fernández-Francos X, Ferrando F, Serra A. New chemically reworkable epoxy coatings obtained by the addition of polyesters with star topologies to diglycidyl ether of bisphenol A resins. Prog Org Coat. 2013;76:1616-1624.

[33]Chen JS, Ober CK, Poliks MD. Characterization of thermally reworkable thermosets: Materials for environmentally friendly processing and reuse. Polymer. 2002;43:131-139.

[34]Chen ]S, Ober CK, Poliks MD, Zhang Y, Wiesner U, Cohen C. Controlled degradation of epoxy networks: Analysis of crosslink density and glass transition temperature changes in thermally reworkable thermosets. Polymer. 2004;45:1939-1950.

[35] Levitas G, De Petris S, Marchetti A, Lazzeri A. Crosslink density and fracture toughness of epoxy resins. ] Mater Sci. 1991;26:2348-2352.

[36]Bagheri R, Marouf BT, Pearson RA. Rubber-toughened epoxies: a critical review. Polymer Rev. 2009;49:201-225.

[37]Arends CB. Polymer toughening. New York: Marcel Dekker, 1996.

[38]Unnikrishnan KP, Thachil ET. Toughening of epoxy resins. Des Monomers Polym. 2006;9:129-152.

[39]Manzione LT, Gillham JK, McPherson CA. Rubber-modified epoxies, I. Transitions and morphology. ] Appl Polym Sci. 1981;26:889-905.

[40]Garg AC, Mai YW. Failure mechanisms in toughened epoxy resins—a review. Compos Sci Technol. 1988;31:179-223.

[41]Ruiz-Pérez L, Royston C], Fairclough JPA, Ryan A]. Toughening by nanostructure. Polymer. 2008;49:4475-4488.

[42]Meng Y, Zhang X-H, Du B-Y, Zhou B-X, Zhou X, Qi G-R. Thermosets with core-shell nanodomain by incorporation of core crosslinked star polymer into epoxy resin. Polymer. 2011;52:391-399.

[43]Mezzenga R, Plummer C]G, Boogh L, Manson JAE. Morphology build-up in dendritic hyperbranched polymer modified epoxy resins: modelling and characterization. Polymer. 2001;42:305-317.

[44]Ratna D, Varley R, Simon GP. Toughening of trifunctional epoxy using an epoxy-functionalized hyperbranched polymer. ] Appl Polym Sci. 2003;89:2339-2345

[45]Boogh L, Pettersson B, Månson J-AE. Dendritic hyperbranched polymers as tougheners for epoxy resins. Polymer. 1999;40:2249-2261. 
[46]Fu ]-F, Shi L-Y, Yuan S, Zhong Q-D, Zhang D-S, Chen Y, et al. Morphology, toughness mechanism, and thermal properties of hyperbranched epoxy modified diglycidyl ether of bisphenol A (DCEBA) interpenetrating polymer networks. Polym Adv Technol. 2008;19:1597-1607.

[47]Zahng D, Chen Y, Jia D. Toughness and reinforcement of diglycidylether of bisphenol A by hyperbranched poly(trimellitic anhydride-butanediol glycol) ester epoxy resin. Polym Compos. 2009;30:918-925.

[48]Mital V. Optimization of polymer nanocomposite properties. Weinheim: Wiley VCH. Chapter 2010.

[49]Chekanov YA, Korotkov VN, Rozenberg BA, Dhzavadyan EA, Bogdanova LM. Cure shrinkage defects in epoxy resins. Polymer 1995; 36 2013-2017.

[50]Sadhir RK, Luck MR. Expanding monomers. Synthesis, characterization and applications. Boca Raton: CRC Press, 1992.

[51]Fernández-Francos X, Salla JM, Cadenato A, Morancho JM, Serra A, Mantecón A. A new strategy for controlling shrinkage of DCEBA resins cured by cationic copolymerization with hydroxyl-terminated hyperbranched polymers and ytterbium triflate as an initiator. ] Appl Polym Sci. 2009;111:2822-2929.

[52]Morell M, Ramis X, Ferrando F, Yu Y, Serra A. New improved thermosets obtained from DCEBA and a hyperbranched poly(esteramide). Polymer. 2009;50:5374-5383.

[53] Khosravi E, Musa OM. Thermally degradable thermosetting materials. Eur Polym ]. 2011;47:465-473.

[54]Tesoro CC, Sastri VR. Reversible crosslinking in epoxy resins. II. New approaches. ] Appl Polym Sci. 1990;39:1439-1457.

[55]Yang S, Chen ]S, Körner H, Breiner T, Ober CK, Poliks MD. Reworkable epoxies: thermosets with thermally cleavable groups for controlled network breakdown. Chem Mater. 1998;10:1475-1482.

[56]Wang L, Li H, Wong CP. Syntheses and characterizations of thermally reworkable epoxy resins. Part 1. ] Polym Sci, Part A: Polym Chem. 1999;37:2991-3001.

[57]Criffith ]R. Epoxy resin chemistry. Washington DC: ACS, 1979.

[58] Buchwalter SL, Kosbar LL. Cleavable epoxy resins: design for disassembly of a thermoset. ] Polym Sci, Part A: Polym Chem. 1996;34:249-260.

[59]Fernández-Francos X, Salla ]M, Mantecón A, Serra A, Ramis X. Crosslinking of mixtures of DCEBA with 1,6-dioxaspiro[4.4]nonan-2,7-dione initiated by tertiary amines, Part II: Thermo-mechanical properties and reworkability. Polym Degrad Stab. 2008;93:760-769.

[60]Seubert C, Nietering K, Nichols M, Wykoff R, Bollin S. An overview of the scratch resistance of automotive coatings: exterior clearcoats and polycarbonate hardcoats. Coatings. 2012;2:221-234.

[61] Mittal V. Polymer nanocomposite coatings. Boca Raton: CRC Press, 2014.

[62] Sangermano M, Messori M. Scratch resistance enhancement of polymer coatings. Macromol Mater Eng. 2010;295:603-612.

[63] Bauer F, Ernst H, Decker U, Findeisen M, Cläsel H-J, Langguth H, et al. Preparation of scratch and abrasion resistant polymeric nanocomposites by monomer grafting onto nanoparticles, 1 FTIR and multi-nuclear NMR spectroscopy to the characterization of methacryl grafting. Macromol Chem Phys. 2000;201:2654-2659.

[64]Mark]E, Lee C, Bianconi PA. Hybrid organic-inorganic composites, vol. 585. Washington, DC: ACS, 1995.

[65]Toselli M, Marini M, Fabbri P, Messori M, Pilati F. J Sol-gel derived hybrid coatings for the improvement of scratch resistance of polyethylene. Sol-Cel Sci Technol. 2007;43:73-83.

[66]Sangermano M, Messori M, Martin Galleco M, Rizza G, Voit B. Scratch-resistant tough nanocomposite epoxy coatings based on hyperbranched polyesters. Polymer. 2009;50:5647-5652.

[67] Sangermano M, El Sayed H, Voit B. Ethoxysilyl-modified hyperbranched polyesters as mulitfunctional coupling agents for epoxy-silica hybrid coatings. Polymer. 2011;52:2103-2109.

[68] Fréchet ]M], Tomalia DA. Dendrimers and other dendritic poymers. Edithvale: John Wiley \& Sons, 2001

[69]Yan D, Gao C, Frey H. Hyperbranched polymers. Synthesis, properties and applications, 1st Hoboken: Wiley Interscience, 2011.

[70]Cong W, Mai Y, Zhou Y, Qi N, Wang B, Yan D. Effect of the degree of branching on atomic-scale free volume in hyperbranched Poly[3-ethyl-3-(hydroxymethyl)oxetane]. A positron study. Macromolecules. 2005;38:9644-9649.

[71] Khalyavina A, Schallausky F, Komber H, Al Samman M, Radke W, Lederer A. Aromatic- aliphatic polyesters with tailored degree of branching based on AB/AB2 and ABB*/AB2 monomers. Macromolecules. 2010;43:3268-3276.

[72] Hawker C], Lee R, Fréchet JM]. One-step synthesis of hyperbranched dendritic polyesters. ] Am Chem Soc. 1991;113:4583-4588.

[73]Yates CR, Hayes W. Synthesis and applications of hyperbranched polymers. Eur Polym ]. 2004;40:1257-1281.

[74] Lyulin AV, Adolf DB, Davies CR. Computer simulations of hyperbranched polymers in shear flows. Macromolecules. 2001;34:3783-3789.

[75]Voit B, Lederer A. Hyperbranched and highly branched polymer architectures—synthetic strategies and major characterization aspects. Chem Rev. 2009;109:5924-5973.

[76]Voit B. Hyperbranched polymers—all problems solved after 15 years of research?] Polym Sci, Part A: Polym Chem. 2005;43:2679-2699. [77]Zheng Y, Li S, Weng Z, Gao C. Hyperbranched polymers: advances from synthesis to applications. Chem Soc Rev. 2015;44:4091-4130.

[78] Kim YH, Webster OW. Hyperbranched polyphenylenes. Macromolecules. 1992;25:5561-5572.

[79]Oh JH, Jang ], Lee S-H. Curing behavior of tetrafunctional epoxy resin/hyperbranched polymer system. Polymer. 2001;42:8339-8347.

[80]Cao C, Yan D. Hyperbranched polymers: from synthesis to applications. Prog Polym Sci. 2004;29:183-275.

[81]Johansson M, Malmström E, Jansson A, Hult A. Novel concept for low temperature curing powder coatings based on hyperbranched polyesters. J Coatings Technol. 2000;72:49-54.

[82]Zhu S-W, Shi W-F. Flame retardant mechanism of hyperbranched polyurethane acrylates used for UV curable flame retardant coatings. Polym Degrad Stab. 2002;75:543-547.

[83] Lange ], Stenroos E, Johansson M, Malmström E. Barrier coatings for flexible packaging. Based on hyperbranched resins. Polymer. 2001;42:7403-7410.

[84]Mishra MK, Kobayashi S. Star and hyperbranched polymers. New York: Marcel Dekker, Inc., 1999.

[85]Aert HAM, Genderen MHP, Meijer EW. Star-shaped poly(2,6-dimethyl-1,4-phenylene ether). Polymer Bull. 1996;37:273-280.

[86]Erwin BM, Cloitre M, Gauthier M, Vlassopoulos D. Dynamics and rheology of colloidal star polymers. Soft Matter. 2010;6:2825-2833. 
[87]Wu W, Wang W, Li ]. Star polymers: advances in biomedical applications. Prog Polym Sci. 2015;46:55-85.

[88]Miao ], Xu G, Zhu L, Tian L, Uhrich KE, Avila-Orta CA, et al. Chain-folding and overall molecular conformation in a novel amphiphilic starlike macromolecule. Macromolecules. 2005;38:7074-7082.

[89]Steege KE, Wang ], Uhrich KE, Castner EW. Local polarity and microviscosity in the hydrophobic cores of amphiphilic star-like and scorpion-like macromolecules. Macromolecules. 2007;40:3739-3748.

[90]Morell M, Foix D, Lederer A, Ramis X, Voit B, Serra A. Synthesis of a new multiarm star polymer based on hyperbranched Poly(styrene) core and Poly(epsilon-Caprolactone) arms and its use as reactive modifier of epoxy thermosets. J Polymer Sci A: Polymer Chem. 2011;49:4639-4649.

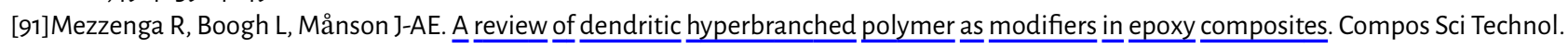
2001;61:787-795.

[92]Hult A, Johansson M, Malmström E. Hyperbranched polymers. Adv Polymer Sci. 1999;143:1-34.

[93] Ratna D, Simon CP. Thermomechanical properties and morphology of blends of a hydroxy-functionalized hyperbranched polymer and epoxy resin. Polymer. 2001;42:8833-8839.

[94] Yang JP, Chen ZK, Yang G, Fu SY, Ye L. Simultaneous improvements in the cryogenic tensile strength, ductility and impact strength of epoxy resins by a hyperbranched polymer. Polymer. 2008;49:3168-3175.

[95]Varley R], Tian W. Toughening of an epoxy anhydride resin system using an epoxidized hyperbranched polymer. Polym Int. 2004;53:69-77.

[96]Foix D, Khalyavina A, Morell M, Voit B, Lederer A, Ramis X, et al. The effect of the degree of branching in hyperbranched polyesters used as reactive modifiers in epoxy thermosets. Macromol Mater Eng. 2012;297:85-94.

[97] Mezzenga R, Boogh L, Månson ]-AE. Evaluation of solubility parameters during polymerisation of amine-cured epoxy resins.] Polymer Sci B: Polymer Phys. 2000;38:1883-1892.

[98]Mezzenga R, Boogh L, Pettersson B, Månson ]-AE. Chemically induced phase separated morphologies in epoxy resin-hyperbranched polymer blends. Macromol Symp. 2000;149:17-22.

[99]Flores M, Fernández-Francos X, Ferrando F, Ramis X, Serra A. Efficient impact resistance improvement of epoxy/anhydride thermosets by adding hyperbranched polyesters partially modified with undecenoyl chains. Polymer. 2012;53:5232-5241.

[100]Flores M, Morell M, Fernández-Francos X, Ferrando F, Ramis X, Serra A. Enhancement of the impact strength of cationically cured cycloaliphatic diepoxide by adding hyperbranched poly(glycidol) partially modified with 10-undecenoyl chains. Eur Polym ]. 2013;49:1610-1620.

[101]Morell M, Erber M, Ramis X, Ferrando F, Voit B, Serra A. New epoxy thermosets modified with hyperbranched poly(ester-amide) of different molecular weight. Eur Polym J. 2010;46:1498-1509.

[102]Tomuta A, Fernández-Francos X, Ferrando F, Serra A, Ramis X. New epoxy-anhydride thermosets modified with multiarm stars with hyperbranched polyester cores and poly(e-caprolactone) arms. Polym Plast Technol Eng. 2014;53:1-10.

[103]Morell M, Fernández-Francos X, Ramis X, Serra A. Synthesis of a new hyperbranched polyaminoester and its use as a $\underline{\text { reactive }} \underline{\text { modifier }} \underline{\text { in }}$ anionic curing of DCEBA thermosets. Macromol Chem Phys. 2010;211:1879-1889.

[104]Morell M, Lederer A, Ramis X, Voit B, Serra A. Multiarm star poly(glycidol)-block-poly(e-caprolactone) of different arm lengths and their use as modifiers of diglycidylether of bisphenol A thermosets. J Polym Sci, Part A: Polym Chem. 2011;49:2395-2406.

[105]Morell M, Fernández-Francos X, Combau ], Ferrando F, Lederer A, Ramis X, et al. Multiarm star poly(glycidol)-block-poly(styrene) as modifier of anionically cured diglycidylether of bisphenol A thermosetting coatings. Prog Org Coat. 2012;73:62-69.

[106]Morell M, Ramis X, Ferrando F, Serra A. New improved thermosets obtained from diglycidylether of bisphenol A and a multiarm star copolymer based on hyperbranched poly(glycidol) core and poly(methylmethacrylate) arms. Macromol Chem Phys. 2012;213:335-343.

[107]Morell M, Ramis X, Ferrando F, Serra A. Effect of polymer topology on the curing process and mechanical characteristics of epoxy thermosets modified with linear or multiarm star poly(e-caprolactone). Polymer. 2011;52:4694-4702.

[108] Lagunas C, Fernández-Francos X, Ferrando F, Flores M, Serra A, Morancho JM, et al. New epoxy thermosets modified with amphiphilic multiarm star polymers as toughness enhancer. React Funct Polym. 2014;83:132-143.

[109] Krämer M, Stumbé ]-F, Grimm G, Kaufmann B, Krüger U, Weber M, et al. Dendritic polyamines:simple access to new materials with defined treelike structures for application in nonviral gene delivery. ChemBioChem. 2004;5:1081-1087.

[110]Available at: http://worldaccount.basf.com/wa/NAFTA en_US/Catalog/ChemicalsNAFTA/pi/BASF/Brand/lupasol/brand_top/. Accesed 18 April 2016.

[111]Tomalia DA, Killat CR. Encyclopedia of Polymer Science and Engineering. Edited by Joseph C. Salamone 2nd ed., Vol. 1 New York: ]ohn Wiley \& Son, $1985: 680-739$.

[112]Dermer OC, Ham GE. Ethylenimine and other aziridines; chemistry and applications. New York: Academic Press. Chapter 41969.

[113]Yemul O, Imae T. Synthesis and characterization of poly(ethyleneimine) dendrimers. Colloid Polym Sci. 2008;286:747-752.

[114]Available at:. Accessed 18 April 2016 http://www.innventia.com/Documents/Rapporter/STFI-Packforsk\%20report\%2032.pdf.

[115]Morrison A, Murray K. The behaviour of oligodeoxynucleotides on thin-layer chromatography on polyethyleneimine-cellulose and ionexchange paper electrophoresis. Biochem ]. 1974;141:321-330.

[116]Ware D, Soane S, Millward DB, Linford MR. US Patent 6.679.924 (to Nano Tex LLC.), 20 January 2004

[117]Bayer LS, Fragouli D, Attanasio A, Sorce B, Bertoni C, Bresci R, et al. Water-repellent cellulose fiber networks with multifunctional properties. Appl Mater Interfaces. 2011;3:4024-4031.

[118]Andrew M, Frederic MS. US Patent 2.472.335, 7 ]une 1949.

[119]Elias H-G, Mülhaupt R. Ullmann's polymer and plastics: Products and processes. Weinheim: Wiley VCH, 2016.

[120]Carmona-Ribeiro AM, Melo LD. Cationic antimicrobial polymers and their assemblies. Int ] Moleuclar Sci. 2013;14:9906-9946.

[121]Bacher K, Schmidt K, Gardin G. US Patent 20.080.199.706, 21 August 2008.

[122]Abdallah B, Hassan A, Benoist C, Coula D, Behr]-P, Demeneix BA. gene transfer into the adult mammalian brain: polyethylenimine. Hum Gene Ther. 1996;7:1947-1954. 
[123]Ma ], Liu Q, Chen D, Zhou Y, Wen S. Carbon dioxide adsorption using amine-functionalized mesocellular siliceous foams. ] Material Sci. 2014;49:7585-7596.

[124] Wang X, Song C, Gaffney AM, Song R. New molecular basket sorbents for CO2 capture based on mesoporous sponge-like TUD-1. Catalysis Today. 2014;238:95-102.

[125] Shi Y, Chen Z, Cheng X, Pan Y, Zhang H, Zhang Z, et al. A novel dual-emission ratiometric fluorescent nanoprobe for sensing and intracellular imaging of $\mathrm{Zn}^{2+}$. Biosens Bioelectron. 2014;61:397-403.

[126]Zheng F, Guo S, Zeng F, Li ], Wu S. Ratiometric fluorescent probe for alkaline phosphatase based on betaine-modified polyethylenimine via excimer/monomer conversion. Anal Chem. 2014;86:9873-9879.

[127] Lin G, Zhu W, Yang L, Wu ], Lin B, Cheng Z, et al. Delivery of siRNA by MRI-visible nanovehicles to overcome drug resistance in MCF-7/ADR human breast cancer cells. Biomaterials. 2014;35:9495-9507.

[128]Chen Y, Gu H, Zhang Z, Li F, Liu T, Xia W. Highly effective inhibition of lung cancer growth and metastasis by systemic delivery of siRNA via multimodal mesoporous silica-based nanocarrier. Biomaterials. 2014;35:10058-10069.

[129]Appelhans D, Komber H, Quadir MA, Richter S, Schwarz S, Van Der Vlist ], et al. Hyperbranched PEl with various oligosaccharide architectures: synthesis, characterization, ATP complexation, and cellular uptake properties. Biomacromolecules. 2009;10:1114-1124.

[130]Strieglera C, Frankea M, Müller M, Boye S, Oertel U, Janke A, et al. Amino acid modified hyperbranched poly(ethylene imine) with disaccharide decoration as anionic core-shell architecture: Influence of the $\underline{\mathrm{pH}}$ and molecular architecture on solution behaviour. Polymer. 2015;80:188-204.

[131]Rumschöttel ], Kosmella S, Prietzel C, Appelhans D, Koetz ]. Change in size, morphology and stability of DNA polyplexes with hyperbranched poly(ethyleneimines) containing bulky maltose units. Colloids Surf, B. 2016;138:78-85.

[132] Bekhradnia S, Naz I, Lund R, Effenberg C, Appelhans D, Sande SA, et al. Characterization of oligosaccharide-functionalized hyperbranched Poly(ethylene Imine) and their complexes With retinol in aqueous solution. J Colloid Interface Sci. 2015;458:178-186.

[133] Hauptmann N, Pion M, Muñoz-Fernández M-Á, Komber H, Werner C, Voit B, et al. Ni(II)-NTA modified Poly(ethylene imine) glycopolymers: physicochemical properties and first in vitro study of polyplexes formed with HIV-derived peptides Macromol Biosci. 2013;13:531-538.

[134] Hauptmann N, Pion M, Wehner R, Muñoz-Fernández M-Á, Schmitz M, Voit B, et al. Potential of Ni(II)-NTA-modified Poly(ethylene imine) glycopolymers as carrier system for future dendritic cell-based immunotherapy. Biomacromolecules. 2014;15:957-967.

[135] Bauman FE, Haeger H, Novikova O, Oenbrink G, Richter R, Finke M. Synthesis and characterization of star-branched PA12 grafted onto PEi core molecule. J Appl Polym Sci. 2004;96:2413-2422.

[136]Cao X, Li Z, Song X, Cui X, Cao P, Liu H, et al. Core-shell type multiarm star poly(ع-caprolactone) with high molecular weight hyperbranched polyethylenimine as core: Synthesis, characterization and encapsulation properties. Eur Polym 1. 2008:44:1060-1070.

[137] Liu H, Shen Z, Stiriba S-E, Chen Y, Zhang W, Wei L. Core-shell-type multiarm star polyethylenimine-block-poly( $\varepsilon$-caprolactone): Synthesis and guest encapsulation potentia. J Polym Sci, Part A: Polym Chem. 2006;44:4165-4173.

[138]Adeli M, Haag R. Multiarm star nanocarriers containing a poly(ethylene imine) core and polylactide arms. ] Polym Sci, Part A: Polym Chem. 2006;44:5740-5749.

[139]Santiago D, Fernández-Francos X, Ramis X, Salla JM, Sangermano M. Comparative curing kinetics and thermal-mechanical properties of DCEBA thermosets cured with a hyperbranched poly (ethyleneimine) and an aliphatic triamine. Thermochim Acta. 2011;526:9-21.

[140]Santiago D, Fernández-Francos X, Ferrando F, De La Flor S. Shape-memory effect in hyperbranched poly(ethyleneimine)-modified epoxy thermosets. J Polym Sci, Part B: Polym Phys. 2015;53:924-933.

[141]Acebo C, Fernández-Francos X, Messori M, Ramis X, Serra A. Shape-memory effect in hyperbranched poly(ethyleneimine)-modified epoxy thermosets. Polymer. 2014;55:5028-5035.

[142]Acebo C, Fernández-Francos X, Santos ]-I, Messori M, Ramis X, Serra A. Shape-memory effect in hyperbranched poly(ethyleneimine)-modified epoxy thermosets. Eur Polym ]. 2015;70:18-27.

[143]Acebo C, Fernández-Francos X, Ramis X, Serra A. Multifunctional allyl-terminated hyperbranched poly(ethyleneimine) as component of new thiol-ene/thiol-epoxy materials. React Funct Polym. 2016;99:17-25.

[144]Acebo C, Fernández-Francos X, Ramis X, Serra A. Thiol-yne/thiol-epoxy hybrid crosslinked materials based on propargyl modified hyperbranched poly(ethyleneimine) and diglycidylether of bisphenol A resins. RSC Adv. 2016;6:61576-61584.

[145]Acebo C, Fernández-Francos X, Ferrando F, Serra A, Salla JM, Ramis X. Thiol-yne/thiol-epoxy hybrid crosslinked materials based on propargyl modified hyperbranched poly(ethyleneimine) and diglycidylether of bisphenol a resins. React Funct Polym. 2013;73:431-441.

[146]Acebo C, Fernández-Francos X, Ferrando F, Serra A, Ramis X. New epoxy thermosets modified with multiarm star poly(lactide) with poly(ethyleneimine) as core of different molecular weight. Eur Polym ]. 2013;49:2316-2326.

[147]Acebo C, Picardi A, Fernández-Francos X, De La Flor S, Ramis X, Serra A. Effect of hydroxyl ended and end-capped multiarm star polymers on the curing process and mechanical characteristics of epoxy/anhydride thermosets. Prog Org Coat. 2014;77:1288-1298.

[148]Acebo C, Alorda M, Ferrando F, Fernández-Francos X, Serra A, Morancho ]M, et al. Epoxy/anhydride thermosets modified with endcapped star polymers with poly(ethyleneimine) cores of different molecular weight and poly(!-caprolactone) arms. Express Polym Lett. 2015;9:809-823.

[149]Mimura K, Ito H, Fujioka H. Improvement of thermal and mechanical properties by control of morphologies in PES-modified epoxy resins. Polymer. 2000;41:4451-4459.

[150]Chikhi N, Fellahi S, Bakar M. Modification of epoxy resin using reactive liquid (ATBN) rubber. Eur Polym ]. 2002;38:251-264.

[151]Däbritz F, Voit B, Naguib M, Sangermano M. Hyperstar poly(ester-methacrylate)s as additives in thermally and photocured epoxy resins. Polymer. 2011;5723-5731.

[152]Foix D, Yu Y, Serra A, Ramis X, Salla JM. Study on the chemical modification of epoxy/anhydride thermosets $\underline{\text { using }} \underline{\text { a hydroxyl terminated }}$ hyperbranched polymer. Eur Polym J. 2009;45:1454-1466.

[153]Foix D, Fernández-Francos X, Salla JM, Serra A, Morancho ]M, Ramis X. New thermosets obtained from bisphenol A diglycidyl ether and hydroxyl-ended hyperbranched polymers partially blocked with benzoyl and trimethylsilyl groups. Polym Int. 2011;60:389-397. 
[154]Fernández-Francos X, Santiago D, Ferrando F, Ramis X, Salla JM, Serra A, et al. Network structure and thermomechanical properties of hybrid DCEBA networks cured with 1-methylimidazole and hyperbranched poly(ethyleneimine)s. ] Polym Sci, Part B: Polym Phys. 2012;50:1489-1503.

[155]Siddhamalli SK, Kyu T. Toughening of thermoset/thermoplastic composites via reaction-induced phase separation: epoxy/phenoxy blends. ] Appl Polym Sci. 2000;77:1257-1268.

[156] Inoue T. Reaction-induced phase decomposition in polymer blends. Prog Polym Sci. 1995;20:119-153.

[157]Fernández-Francos X, Foix D, Serra A, Salla JM, Ramis X. Novel thermosets based on DCEBA and hyperbranched polymers modified with vinyl and epoxy end groups. React Funct Polym. 2010;70:798-806.

[158]]ohnson TW, Klotz IM. Preparation and characterization of some derivatives of poly(ethylenimine). Macromolecules. 1974;7:149-153.

[159]Antonietti L, Aymonier C, Schlotterbeck U, Caramus VM, Maksimova T, Richtering W, et al. Core-shell-structured highly branched poly(ethylenimine amide)s: synthesis and structure. Macromolecules. 2005;14:5914-5920.

[160] Liu H, Chen Y, Zhu D, Shen Z, Stiriba S-E. Hyperbranched polyethylenimines as versatile precursors for the preparation of different type of unimolecular micelles. React Funct Polym. 2007;67:383-395.

[161] Qin H, Liu H, Chen Y. Influence of aliphatic amide terminals on the thermoresponsive properties of hyperbranched polyethylenimines. Chin ] Polym Sci. 2014;32:1338-1347.

[162]Thetford D, Schofield JD. US Patent 5.700.395, 23 December 1997.

[163]Kasza G, Mosnácková K, Nádor A, Osváth Z, Stumphauser T, Szarka G, et al. Hyperbranched polyethylenimines as versatile precursors for the preparation of different type of unimolecular micelles. Eur Polym ]. 2015;68:609-617.

[164]Montalbetti CACN, Falque V. Amide bond formation and peptide coupling. Tetrahedron. 2015;61:10827-10852.

[165]Acebo C, Fernández-Francos X, De La Flor S, Ramis X, Serra A. New anhydride/epoxy thermosets based on diglycidyl ether of bisphenol A and 10-undecenoyl modified poly(ethyleneimine) with improved impact resistance. Prog Org Coat. 2015;85:52-59.

[166] Liu ], Duong H, Whittaker MR, Davis TP, Boyer C. Synthesis of functional core, star polymers via RAFT polymerization for drug delivery applications. Macromol Rapid Commun. 2012;33:760-766.

[167] Rodionov V, Gao H, Scroggins S, Unruh DA, Avestro A-], Fréchet ]M]. Easy access to a family of polymer catalysts from modular star polymers. J Am Chem Soc. 2010;132:2570-2572.

[168] Xia W, Jiang G, Chen W. Synthesis and drug-release properties of hyperbranched polyesters grafted with biocompatible poly $(\epsilon-$ caprolactone). J Appl Polym Sci. 2008;109:2089-2094.

[169]Zhang X, Cheng ], Wang Q, Zhong Z, Zhuo R. Miktoarm copolymers bearing one poly(ethylene glycol) chain and several poly( $\underline{\text { c- }}$ caprolactone) chains on a hyperbranched polyglycerol core. Macromolecules. 2010;43:6671-6677.

[170]Cameron D]A, Shaver MP. Aliphatic polyester polymer stars: synthesis, properties and applications in biomedicine and nanotechnology. Chem Soc Rev. 2011;40:1761-1776.

[171]Duréault A, Taton D, Destarac M, Leising F, Gnanou Y. Synthesis of multifunctional dithioesters using tetraphosphorus decasulfide and their behavior as RAFT agents. Macromolecules. 2004;37:5513-5519.

[172] Maier S, Sunder A, Frey H, Mülhaupt R. Synthesis of poly(glycerol)-block-poly(methyl acrylate) multi-arm star polymers. Macromol Rapid Commun. 2000;21:226-230.

[173] Trollsås M, Hawker C], Remenar JF, Hedrick ]L, Johanson H, Ihre H, et al. Highly branched radial block copolymers via dendritic initiation of aliphatic polyesters. J Polym Sci, Part A: Polym Chem. 1998;36:2793-2798.

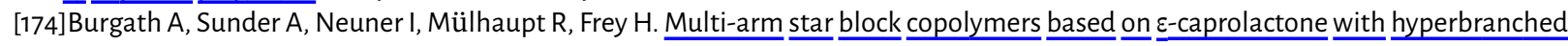
polyglycerol core. Macromol Chem Phys. 2000;201:792-797.

[175]Cao PF, Xiang R, Liu XY, Zhang CX, Cheng F, Chen Y]. Modulating the guest encapsulation and release properties of multi-arm star polyethylenimine-block-poly (E-caprolactone).] Polym Sci, Part A: Polym Chem. 2009;47:5184-5193

[176] Schömer M, Frey H. Organobase-catalyzed synthesis of multiarm star polylactide with hyperbranched poly(ethylene glycol) as the core. Macromol Chem Phys. 2011;212:2478-2486.

[177]Biela T, Kowalski A, Libiszowski ], Duda A, Penczek S. Progress in polymerization of cyclic esters: mechanisms and synthetic applications Macromol Symp. 2006;240:47-55.

[178] Kowalski A, Libiszowski ], Biela T, Cypryk M, Duda A, Penczek S. Kinetics and mechanism of cyclic esters polymerization initiated with Tin(II) octoate. Polymerization of $\varepsilon$-Caprolactone and I,I-Lactide co-initiated with primary amines. Macromolecules. 2005;38:8170-8176.

[179] Hameed N, Guo Q, Hanley T, Mai YW. J Polym Sci, Part B: Hydrogen bonding interactions, crystallization, and surface hydrophobicity in nanostructured epoxy/block copolymer blends. Polym Phys. 2010;48:790-800.

[180] Lützen H, Bitomsky P, Rezwan K, Hartwig A. Partially crystalline polyols lead to morphology changes and improved mechanical properties of cationically polymerized epoxy resins. Eur Polym J. 2013;49:167-176.

[181].Chen JS, Ober CK, Poliks MD. Characterization of thermally reworkable thermosets: materials for environmentally friendly processing and reuse. Polymer. 2002;43:131-139.

[182] Meng F, Xu Z, Zheng S. Microphase separation in thermosetting blends of epoxy resin and poly(E-caprolactone)-block-polystyrene block copolymers. Macromolecules. 2008;41:1411-1420.

[183]Chruściel ]], Leśniak E. Modification of epoxy resins with functional silanes, polysiloxanes, silsesquioxanes, silica and silicates. Prog Polym Sci. 2015;41:67-121.

[184]Pierre AC. New types of sol-gel derived materials. In: Pierre AC, editor. Introduction to sol-gel processing. Norwell: Kluver Academic, 1998.

[185] Gröhn F, Kim G, Bauer B], Amis E]. Nanoparticle formation within dendrimer-containing polymer networks: route to new organic-inorganic hybrid materials. Macromolecules. 2001;34:2179-2185.

[186]Matejka L, Dukh O, Kolarik ]. Reinforcement of crosslinked rubbery epoxies by in-situ formed silica. Polymer. 2000;41:1449-1459.

[187]Wen ], Wilkes CL. Organic/inorganic hybrid network materials by the sol-gel approach. Chem Mater. 1996;8:1667-1681.

[188]Ceorgieva N, Bryaskova R, Tzoneva R. New polyvinyl alcohol-based hybrid materials for biomedical application. Material Lett. 2012;88:19-22. 
[189]Matějka L, Pleštil ], Dušek K. Structure evolution in epoxy-silica hybrids: sol-gel process. ] Non Cryst Solids. 1998;226:114-121. [190]Silva CR, Airoldi C. Acid and Base Catalysts in the Hybrid Silica Sol-Gel Process. ] Colloid Interface Sci. 1997;195:381-387.

[191]Serra A, Ramis X, Fernández-Francos X. Epoxy sol-gel hybrid thermosets. Coatings. 2016;6:8.

[192] Branda F, Tescione F, Ambrogi V, Sannino D, Silvestri B, Luciani C, et al. A new extra situ sol-gel route to silica/epoxy (DCEBA) nanocomposite. A DTA study of imidazole cure kinetic. Polymer Bull. 2011;66:1289-1300.

[193] Beneŝ H, Galy ], Cérard J-F, Pleŝtil ], Valette L. Preparation and characterization of organic/inorganic hybrid epoxy networks from reactive inorganic precursors. ] Appl Polym Sci. 2012;125:1000-1011.

[194] Pisticelli F, Lavorgna M, Buonocore CG, Verdolotti L, Galy ], Mascia L. Plasticizing and reinforcing features of siloxane domains in aminecured epoxy/silica hybrids. Macromol Mater Eng. 2013;298:896-909.

[195]Davis SR, Brough AR, Atkinson A. Formation of silica/epoxy hybrid network polymers. ] Non-Cryst Solids. 2003;315:197-205.

[196] Prezzi L, Mascia L. Network density control in epoxy-silica hybrids by selective silane functionalization of precursors. Adv Polymer Technol. 2005;24:91-102.

[197]Palraj S, Selvaraj M, Maruthan K, Rajagopal C. Corrosion and wear resistance behavior of nano-silica epoxy composite coatings. Prog Org Coat. 2015;81:132-139.

[198]Kaneko Y, Shoirikia M, Mizumob T. Preparation of cage-like octa(3-aminopropyl)silsesquioxane trifluoromethanesulfonate in higher yield with a shorter reaction time. ] Mater Chem. 2012;22:14475-14478.

[199]Chruściel J], Leśniak E. Modification of epoxy resins with functional silanes, polysiloxanes, silsesquioxanes, silica and silicates. Prog Polym Sci. 2015;41:67-121.

[200]Choi ], Harcup ], Yee AF, Zhu Q, Laine RM. Organic/inorganic hybrid composites from cubic silsesquioxanes. ] Am Chem Soc. 2001;123:11420-11430.

[201] Houel A, Galy ], Charlot A, Cérard ]-F. Synthesis and characterization of hybrid films from hyperbranched polyester using a sol-gel process. J Appl Polym Sci 2014. DOI: 10.1002/app.39830. DOI:10.1002/app.39830.

[202]Ceiser V, Letterrier Y, Månson ]-AE. Low-stress hyperbranched polymer/silica nanostructures produced by UV curing, sol/gel processing and nanoimprint lithography. Macromol Mater Eng. 2012;297:155-166.

[203]Allauddin S, Chandran MKA, Jena KK, Narayan R, Raju KVSN. Synthesis and characterization of APTMS/melamine cured hyperbranched polyester-epoxy hybrid coatings. Prog Org Coat. 2013;76:1402-1412.

[204] Lorenzo V, Acebo C, Ramis X, Serra A. Synthesis and characterization of APTMS/melamine cured hyperbranched polyester-epoxy hybrid coatings. Prog Org Coat. 2016;92:16-22.

[205] Kolb HC, Finn MG, Sharpless KB. Click chemistry: diverse chemical function from a few good reactions. Ange Chem Int Ed. 2001;40:2004-2021.

[206] Franc G, Kakkar AK. Diels-Alder “Click" chemistry in designing dendritic macromolecules. Chem Eur ]. 2009;15:5630-5639.

[207]Voit B. The potential of cycloaddition reactions in the synthesis of dendritic polymers. New ] Chem. 2007;31:1139-1151.

[208] Kumaraswamy C, Ankamma K, Pitchaiah A. Tandem epoxide or aziridine ring opening by azide/copper catalyzed [3+2] cycloaddition: efficient synthesis of 1,2,3-triazolo $\beta$-hydroxy or $\beta$-tosylamino functionality motif. J Org Chem. 2007;72:9822-9825.

[209] Heredia KL, Tolstyka ZP, Maynard HD. Aminooxy end-functionalized polymers synthesized by ATRP for chemoselective conjugation to proteins. Macromolecules. 2007;40:4772-4779.

[210] Hoyle CE, Lowe AB, Bowman CN. Thiol-click chemistry: a multifaceted toolbox for small molecule and polymer synthesis. Chem Soc Rev. 2010;39:1355-1387.

[211]Tasdelena MA, Kiskanb B, Yagci Y. Externally stimulated click reactions for macromolecular syntheses. Prog Polym Sci. 2016;52:19-78.

[212]Wong C-H, Zimmerman SC. Orthogonality in organic, polymer, and supramolecular chemistry: from Merrifield to click chemistry. Chem Commun. 2013;49:1679-1695.

[213] Lutz ]-F, Börner HC, Weichenhan K. Combining ATRP and "Click" chemistry: a promising platform toward functional biocompatible polymers and polymer bioconjugates. Macromolecules. 2006;39:6376-6383.

[214]Iha RK, Wooley KL, Nyström AM, Burke D], Kade M], Hawker C]. Applications of orthogonal "click" chemistries in the synthesis of functional soft materials. Chem Rev. 2009;109:5620-5686.

[215] Kolb HC, Sharpless KB. The growing impact of click chemistry on drug discovery. Drug Discov Today. 2003;8:1128-1137.

[216]Xi W, Scott TF, Kloxin C], Bowman CN. Click chemistry in materials science. Adv Funct Mater. 2014;24:2572-2590.

[217]Thirumurugan P, Matosiuk D, Jozwiak K. Click chemistry for drug development and diverse chemical-biology applications. Chem Rev. 2013;113:4905-4979.

[218]Chen G], Tao L, Mantovani G, Ladmiral V, Burt DP, Macpherson JV, et al. Synthesis of azide/alkyne-terminal polymers and application for surface functionalisation through a [2 +3] Huisgen cycloaddition process, "click chemistry". Soft Matter. 2007;3:732-739.

[219] Nischang I, Brueggemann O, Teasdale I. Facile, single-step preparation of versatile, high-surface-area, hierarchically structured hybrid materials. Ange Chem Int Ed. 2011;50:4592-4596.

[220]De Forest CA, Anseth KS. Cytocompatible click-based hydrogels with dynamically-tunable properties through orthogonal photoconjugation and photocleavage reactions. Nat Chem. 2011;3:925-931.

[221]Zhang Q, Ning Z], Yan YL, Qian SX, Tian H. Photochromic spiropyran dendrimers: 'Click' syntheses, characterization, and optical properties. Macromol Rapid Commun. 2008;29:193-201.

[222] Li HM, Cheng FO, Duft AM, Adronov A. Functionalization of single-walled carbon nanotubes with well-defined polystyrene by "Click" coupling. J Am Chem Soc. 2005;127:14518-14524.

[223]]ian Y, He Y, Sun Y, Yang H, Yang W, Nie ]]. Thiol-epoxy/thiol-acrylate hybrid materials synthesized by photopolymerization. Mater Chem C. 2013;1:4481-4489.

[224]De S, Khan A. Efficient synthesis of multifunctional polymersviathiol-epoxy "click" chemistry. Chem Commun. 2012;48:3130-3132

[225]Yuan YC, Rong MZ, Zhang MQ, Chen ], Yang CC, Li XM. Self-healing polymeric materials using epoxy/mercaptan as the healant. Macromolecules. 2008;41:5197-5202. 
[226]]in K, Heath WH, Torkelson JM. Kinetics of multifunctional thiol-epoxy click reactions studied by differential scanning calorimetry: effects of catalysis and functionality. Polymer. 2015;81:70-78.

[227]Fernández-Francos X, Konuray A-O, Belmonte A, De La Flor S, Serra A, Ramis X. Sequential curing of off-stoichiometric thiol-epoxy thermosets with a custom-tailored structure. Polym Chem. 2016;7:2280-2290.

[228] Hoyle CE, Bowman CN. Thiol-ene click chemistry. Ange Chem Int Ed. 2010;49:1540-1573.

[229] Hoyle CE, Lee TY, Roper T. Thiol-enes: chemistry of the past with promise for the future. J Polym Sci, Part A: Polym Chem. 2004;42:5301-5338.

[230] Lowe AB, Bowman CN. 2013. Thiol-X Chemistries in polymer and material science. Croydon: RSC Publishing

[231]Sprafke ]K, Spruell JM, Mattson KM, Montarnal D, McGrath A], Pötzsch R, et al. Revisiting thiol-yne chemistry: selective and efficient monoaddition for block and graft copolymer formation. J Polym Sci, Part A: Polym Chem. 2015;53:319-326.

[232] Killops KL, Campos LM, Hawker C]. Robust, efficient, and orthogonal synthesis of dendrimers via thiol-ene "click" chemistry. ] Am Chem Soc. 2008;130:5062-5064.

[233]Chan JW, Zhou H, Hoyle CE, Lowe AB. Photopolymerization of thiol-alkynes: polysulfide networks. Chem Mater. 2009;21:1579-1585.

[234]Wei Q, Pötzsch R, Liu X, Komber H, Kiriy A, Voit B, et al. Hyperbranched polymers with high transparency and inherent high refractive index for application in organic light-emitting diodes. Adv Funct Mater 2016;26:2545-2553

[235]Cramer NB, Scott ]P, Bowman CN. Photopolymerizations of thiol-ene polymers without photoinitiators. Macromolecules. 2002;35:5361-5365.

[236] Lowe AB. Polymer. Thiol-yne 'click'/coupling chemistry and recent applications in polymer and materials synthesis and modification. 2014;55:5517-5549.

[237]Sangermano M, Roppolo I, Acosta Ortiz R, Navarro Tovar AG, García Valdez AE, Berlanga Duarte L. Interpenetrated hybrid thiolene/epoxy Uv-cured network withenhanced impact resistance. Prog Org Coat. 2015;78:244-248.

[238] Carioscia ]A, Stansbury JW, Bowman CN. Evaluation and control of thiol-ene/thiol-epoxy hybrid networks. Polymer. 2007:48:1526-1532.

[239]]ian Y, He Y, Sun Y, Yang H, Yang W, Nie J. ] Mater Chem C. Thiol-epoxy/thiol-acrylate hybrid materials synthesized by photopolymerization. 2013;1:4481-4489.

[240]Yoshimura T, Shimasaki T, Teramoto N, Shibata M. Bio-based polymer networks by thiol-ene photopolymerizations of allyl-etherified eugenol derivatives. Eur Polym J. 2015;67:397-408.

[241] Nair DP, Cramer NB, Gaipa JC, McBride MK, Matherly EM, McLeod RR, et al. Two-stage reactive polymer network forming systems. Adv Funct Mater. 2012;22:1502-1510.

[242]Miller DR, Valles EM, Macosko CW. Calculation of molecular parameters for stepwise polyfunctional polymerization. Polymer Eng Sci. 1979;19:272-283.

[243]Cuzmán D, Ramis X, Fernández-Francos X, Serra A. Preparation of click thiol-ene/thiol-epoxy thermosets by controlled photo/thermal dual curing sequence. RSC Adv. 2015;5:101623-101633. 